\title{
Assembly of Conjugated Enynes and Substituted Indoles via CuI/Amino acid Catalyzed Coupling of 1-Alkynes with Vinyl Iodides and 2-Bromotrifluoroacetanilides
}

\author{
Feng Liu and Dawei Ma* \\ State Key Laboratory of Bioorganic and Natural Products Chemistry, Shanghai \\ Institute of Organic Chemistry, Chinese Academy of Sciences, 354 Fenglin Lu, \\ Shanghai 200032, China
}

Supporting Information

Table of contents

Copies of ${ }^{1} \mathrm{H}$ NMR and ${ }^{13} \mathrm{C}$ NMR spectrum of all new compounds---------------S2-S48 

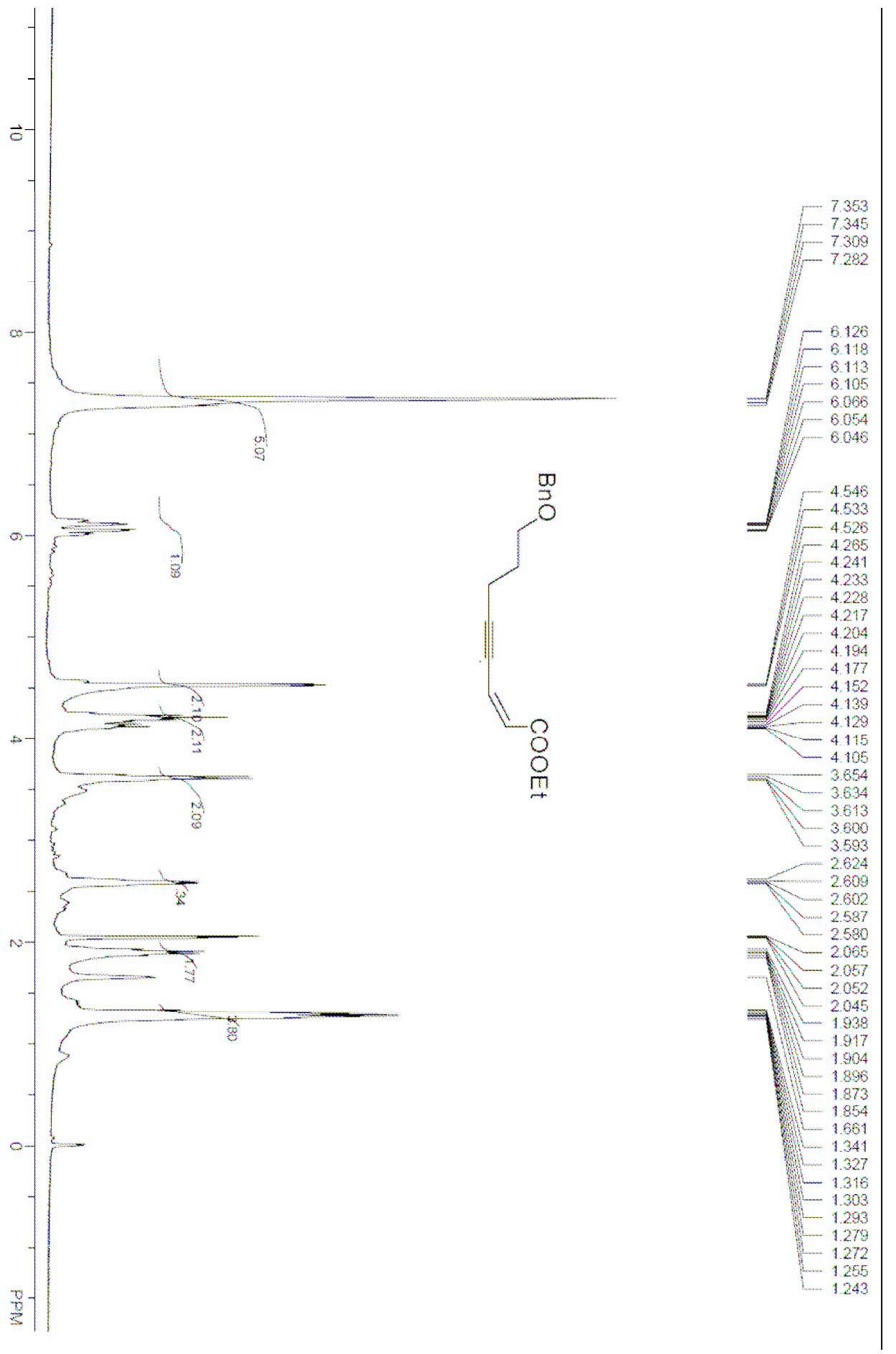


$$
\mid
$$




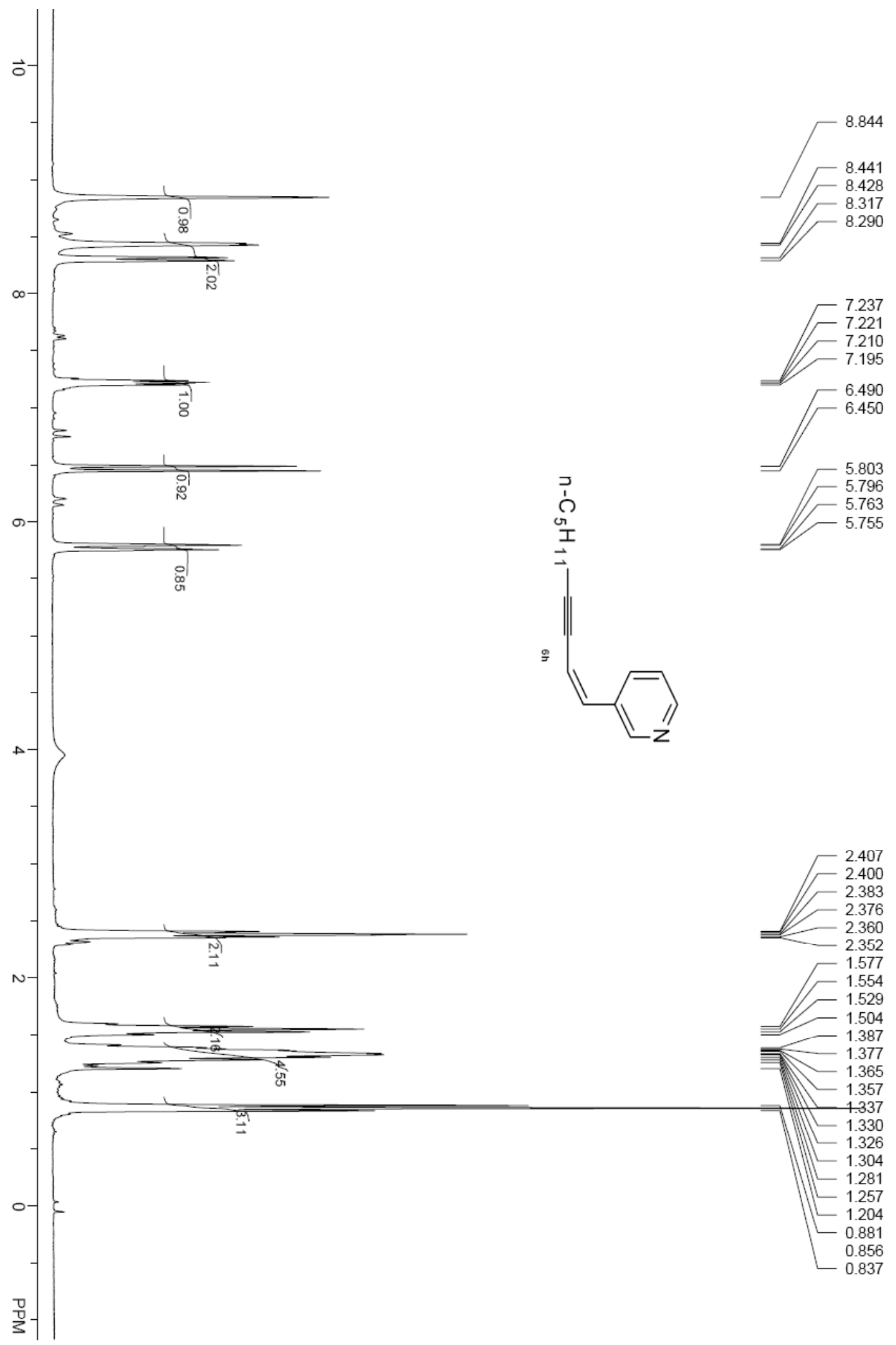



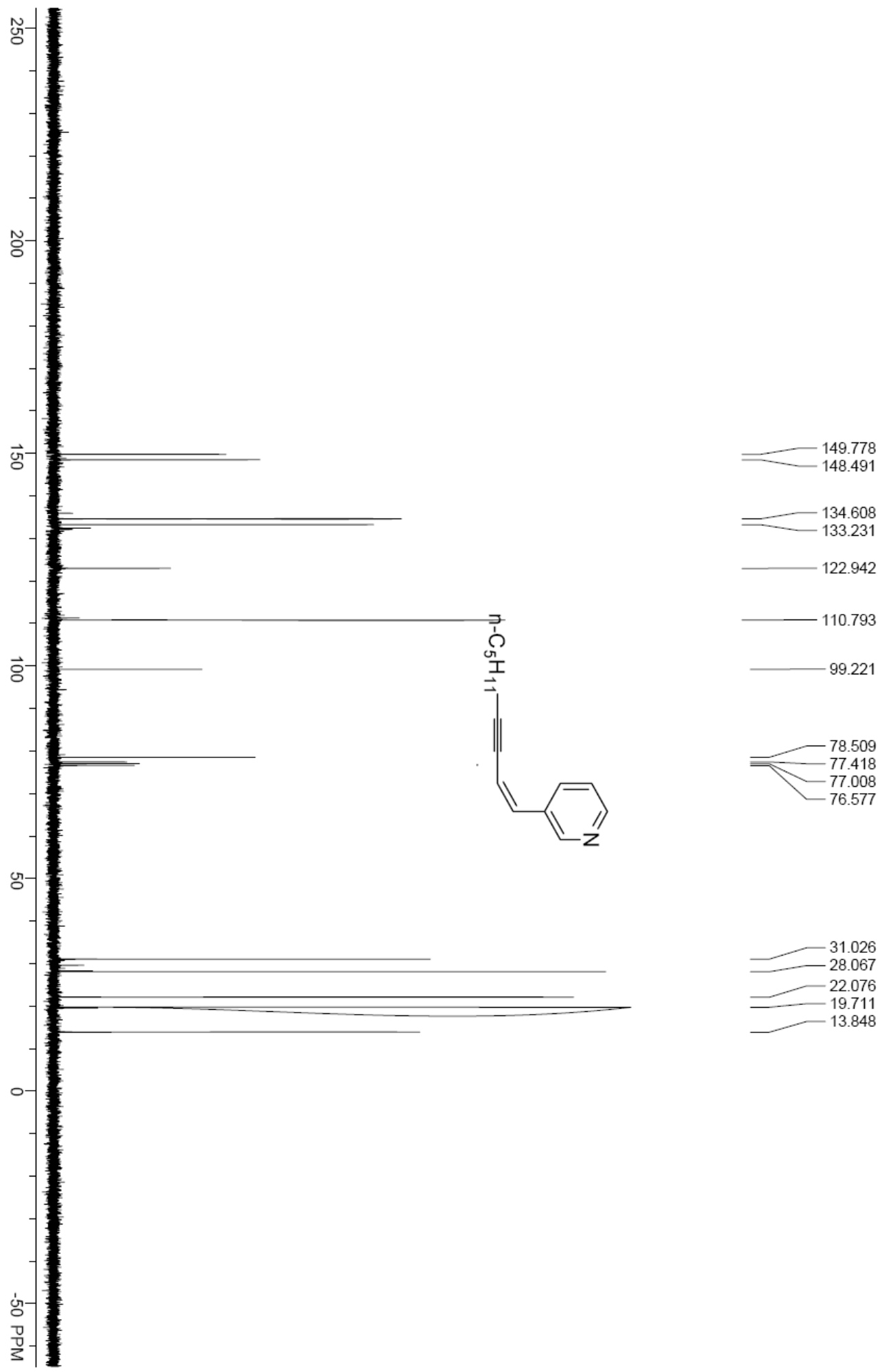

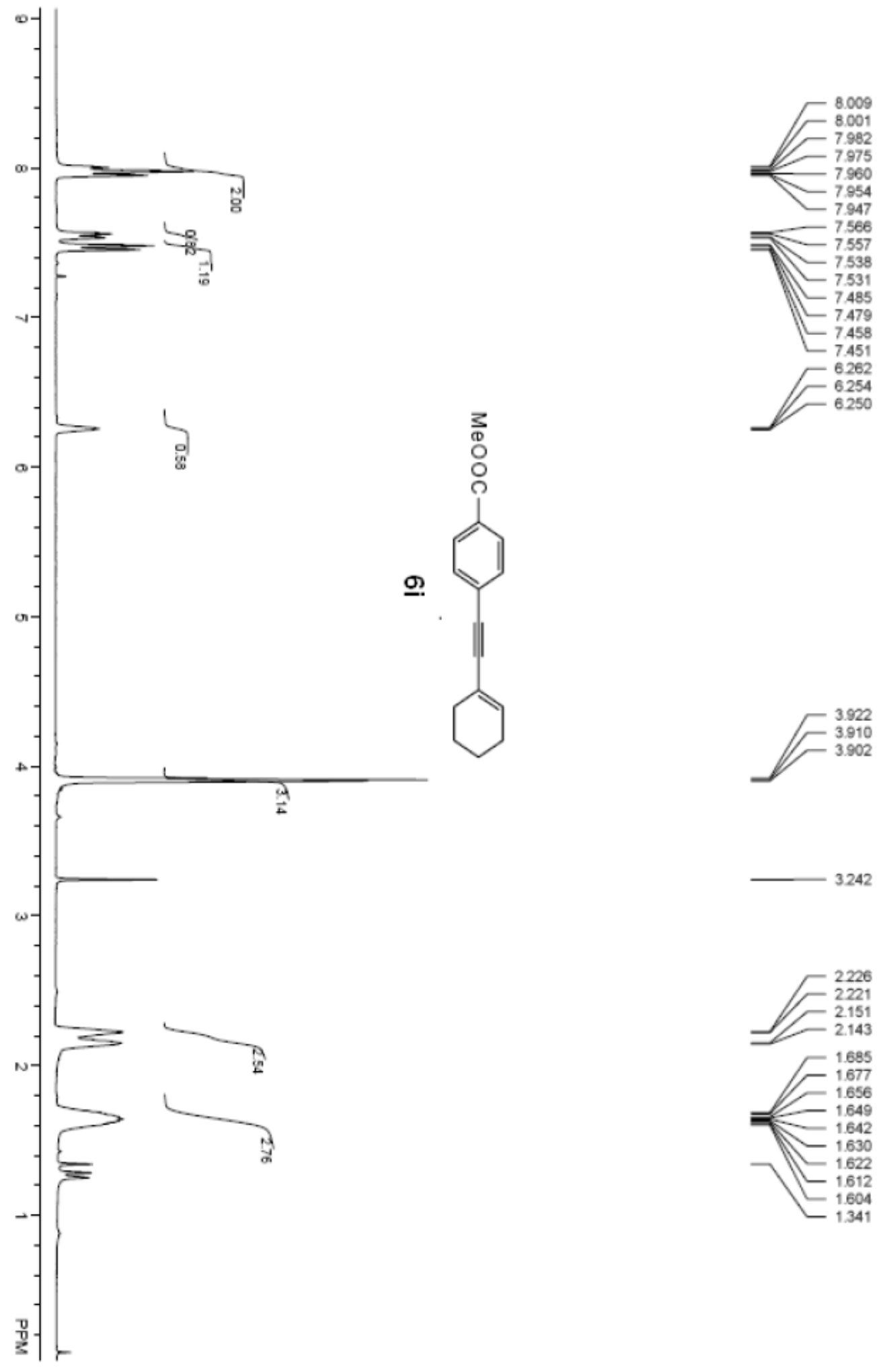


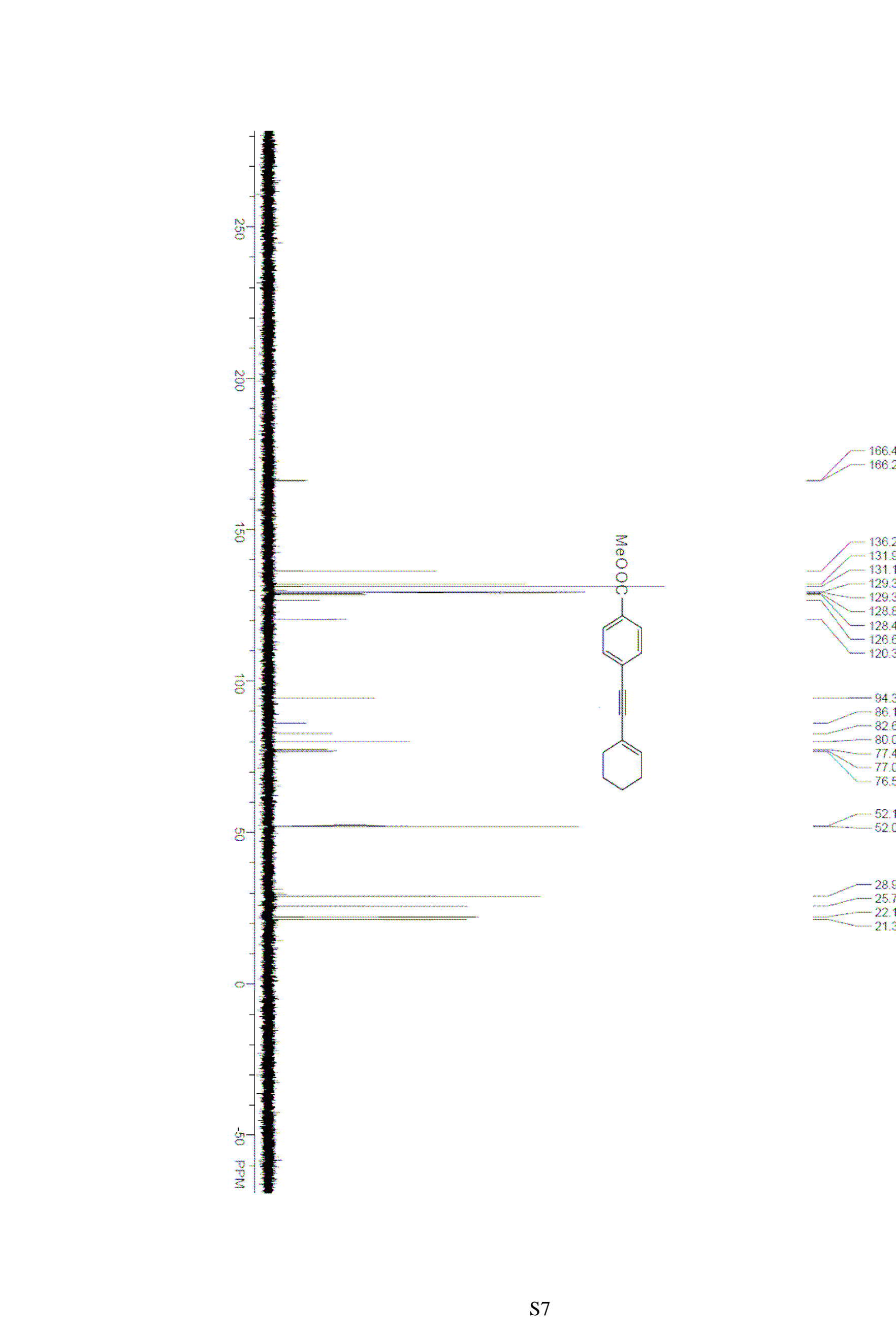



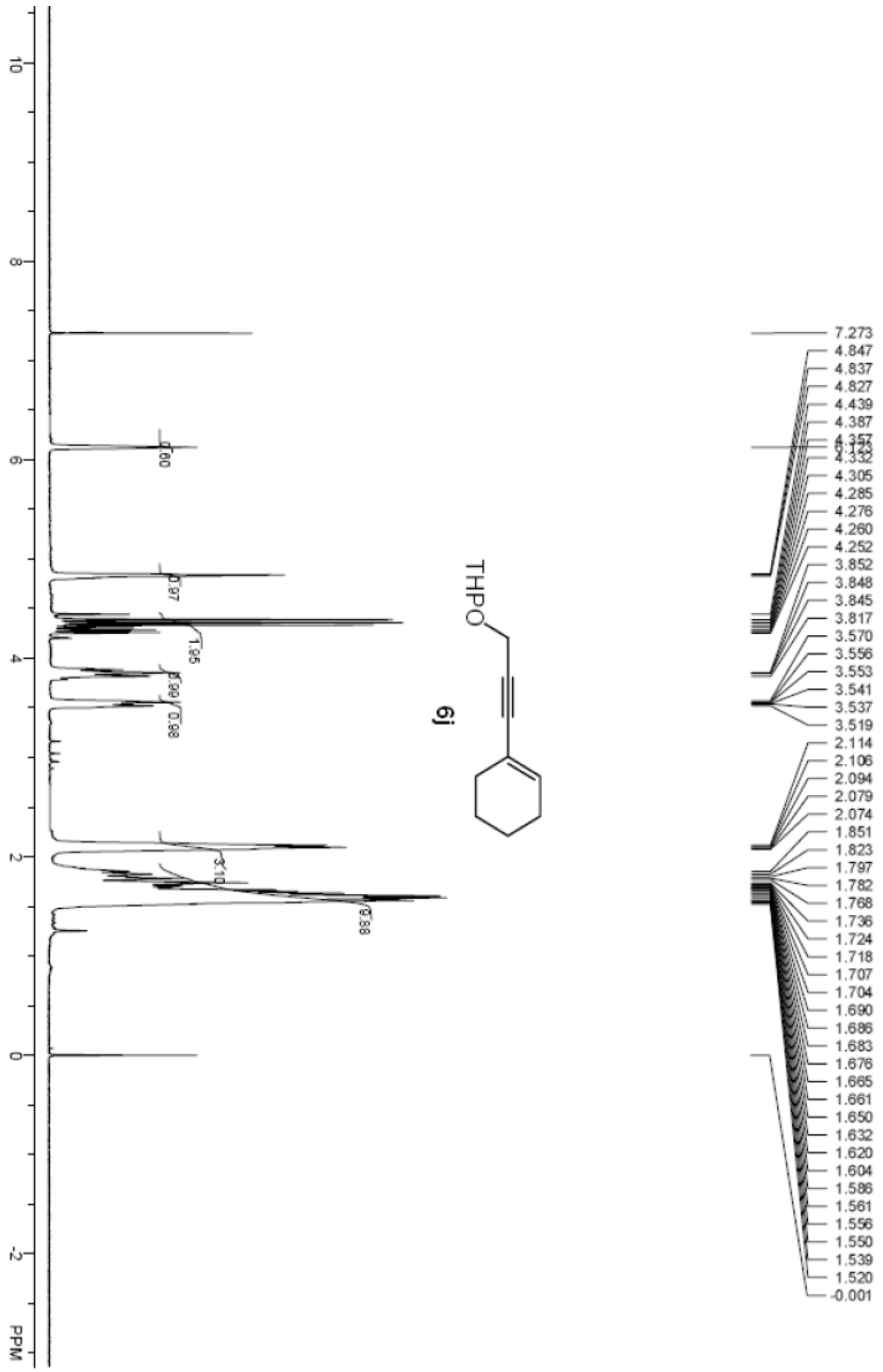


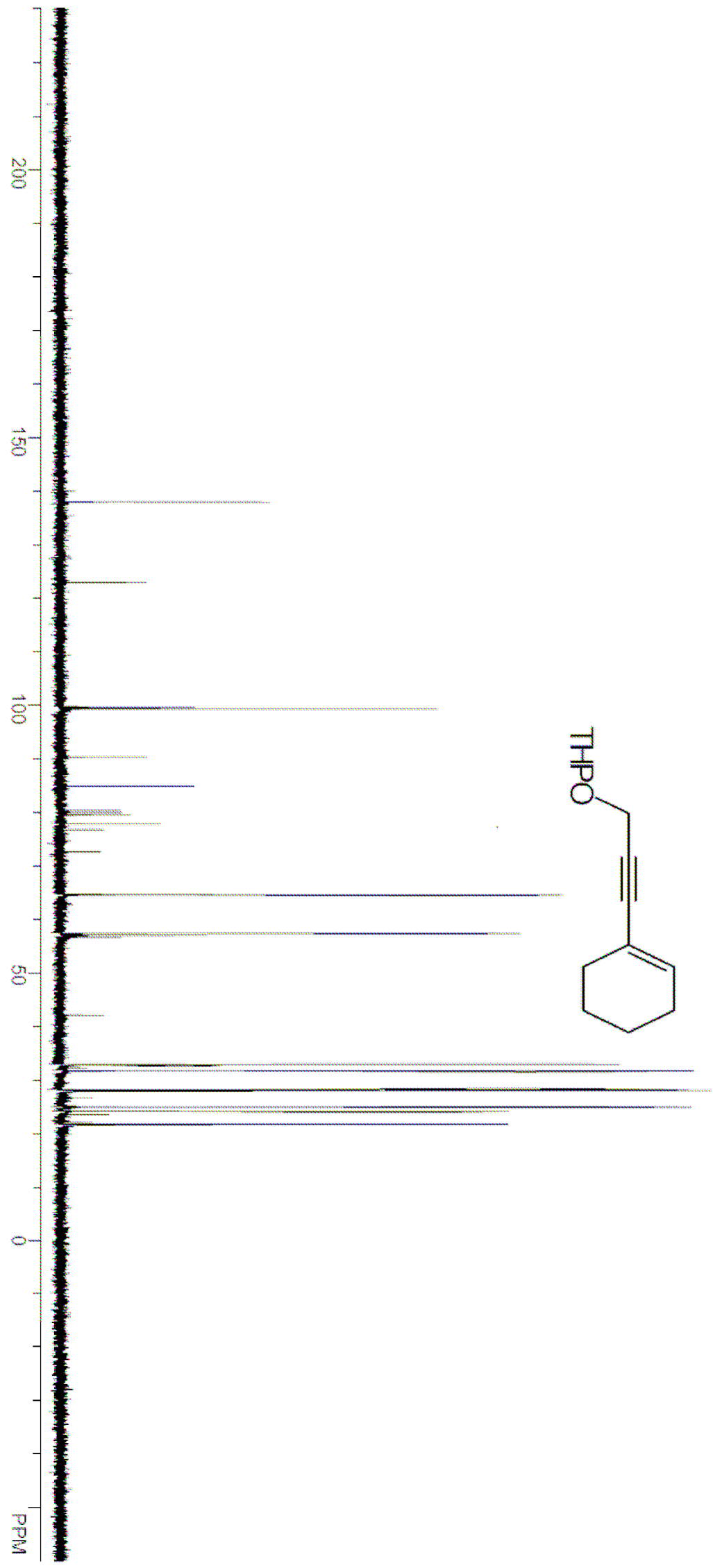

137.887

122.891
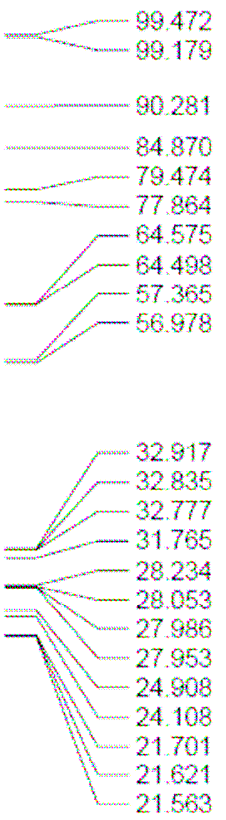


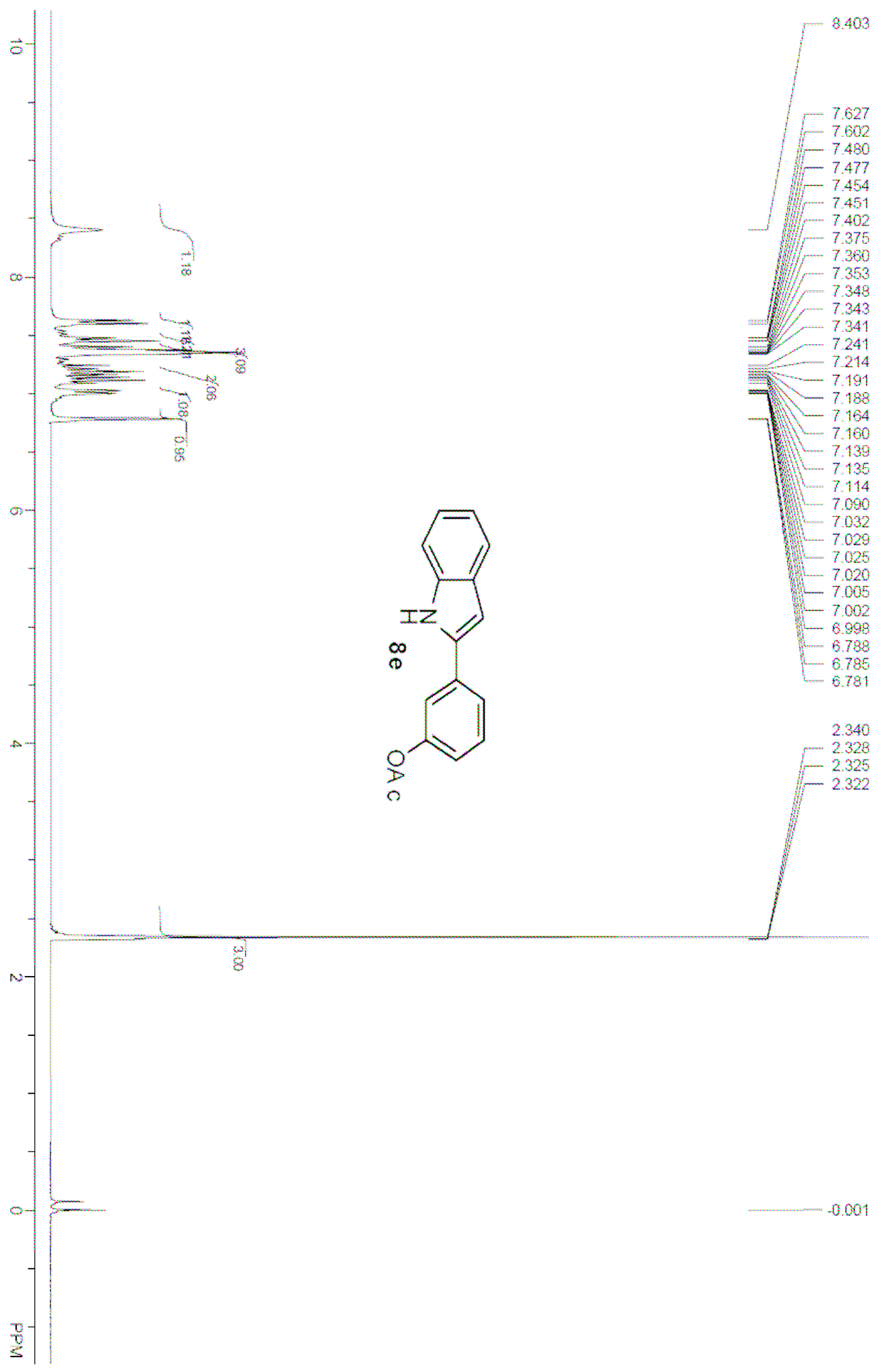




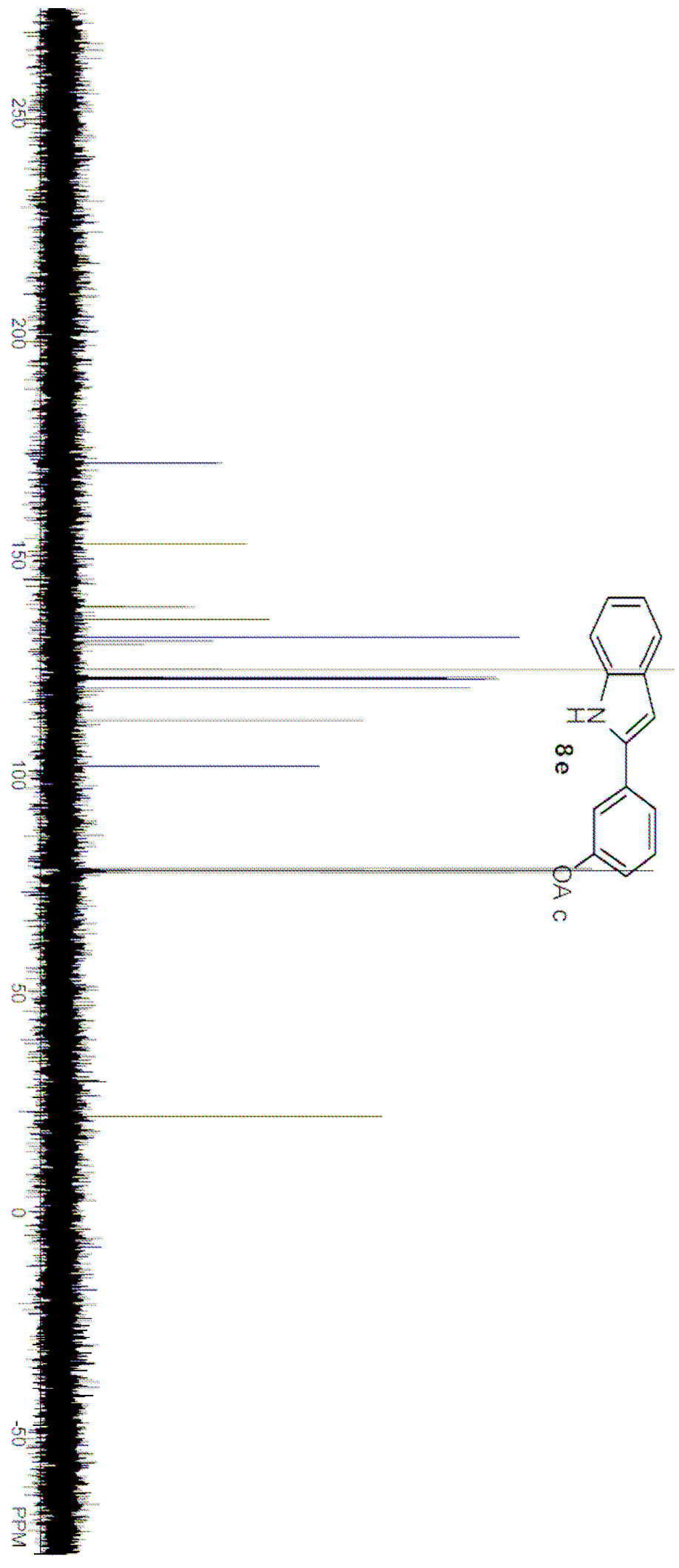

$-169.914$

151.631

$-137.265$

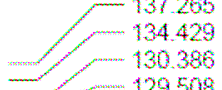

129508

128801 122.984 121,173 12102 20.713 118.734 $-111.39$ $-101043$ $-77.841$ $-77.419$

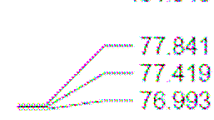



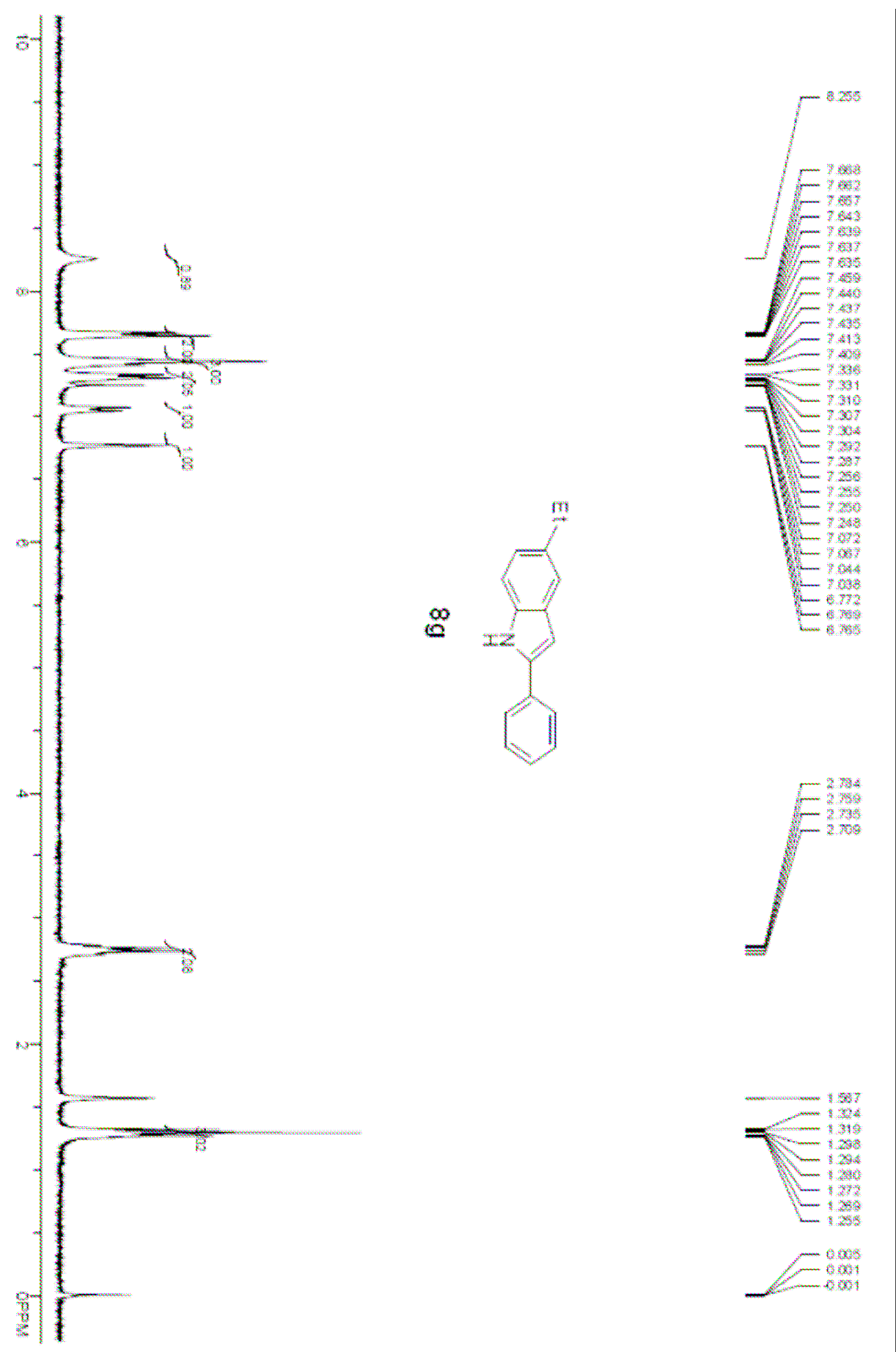

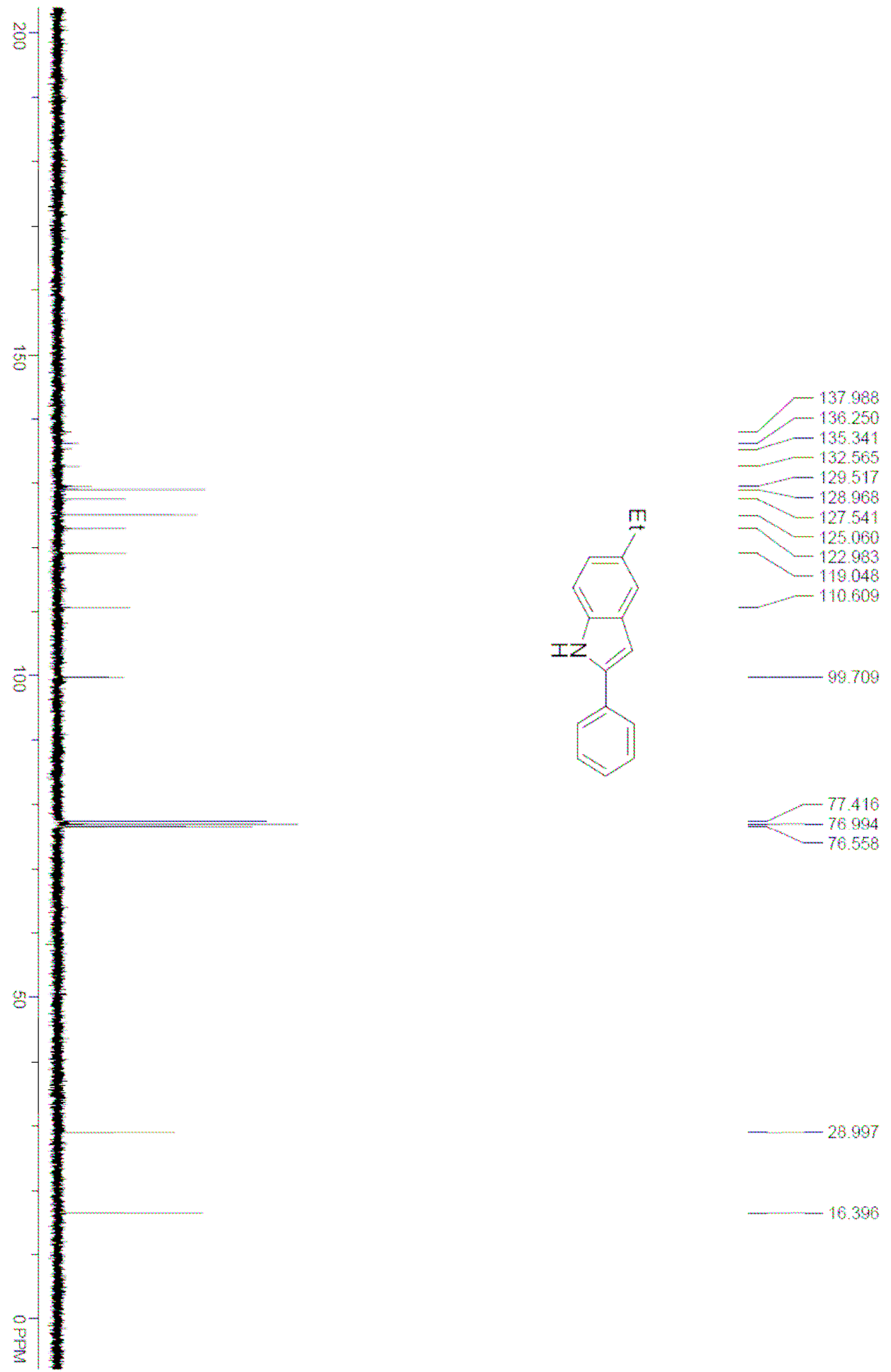

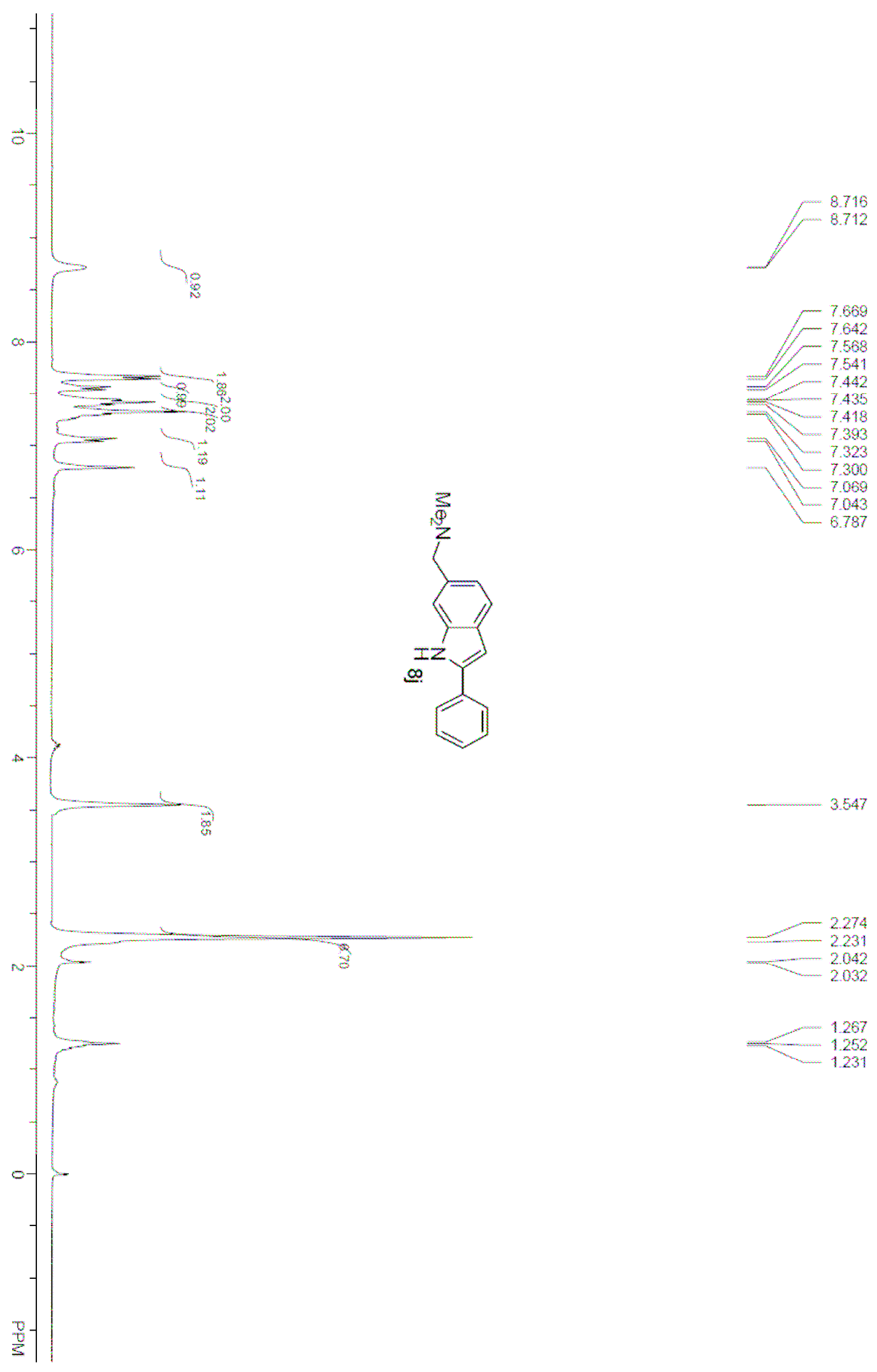

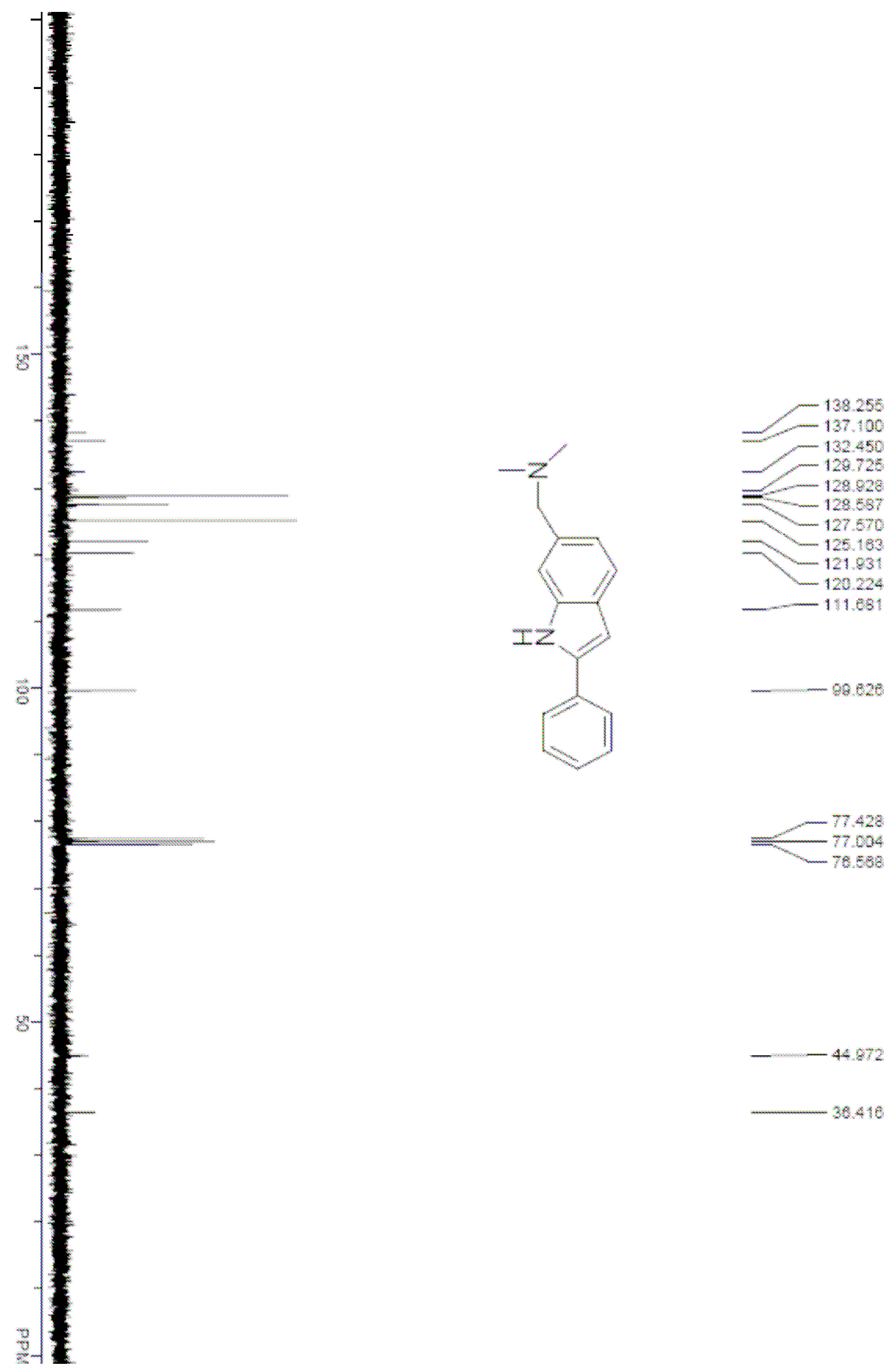

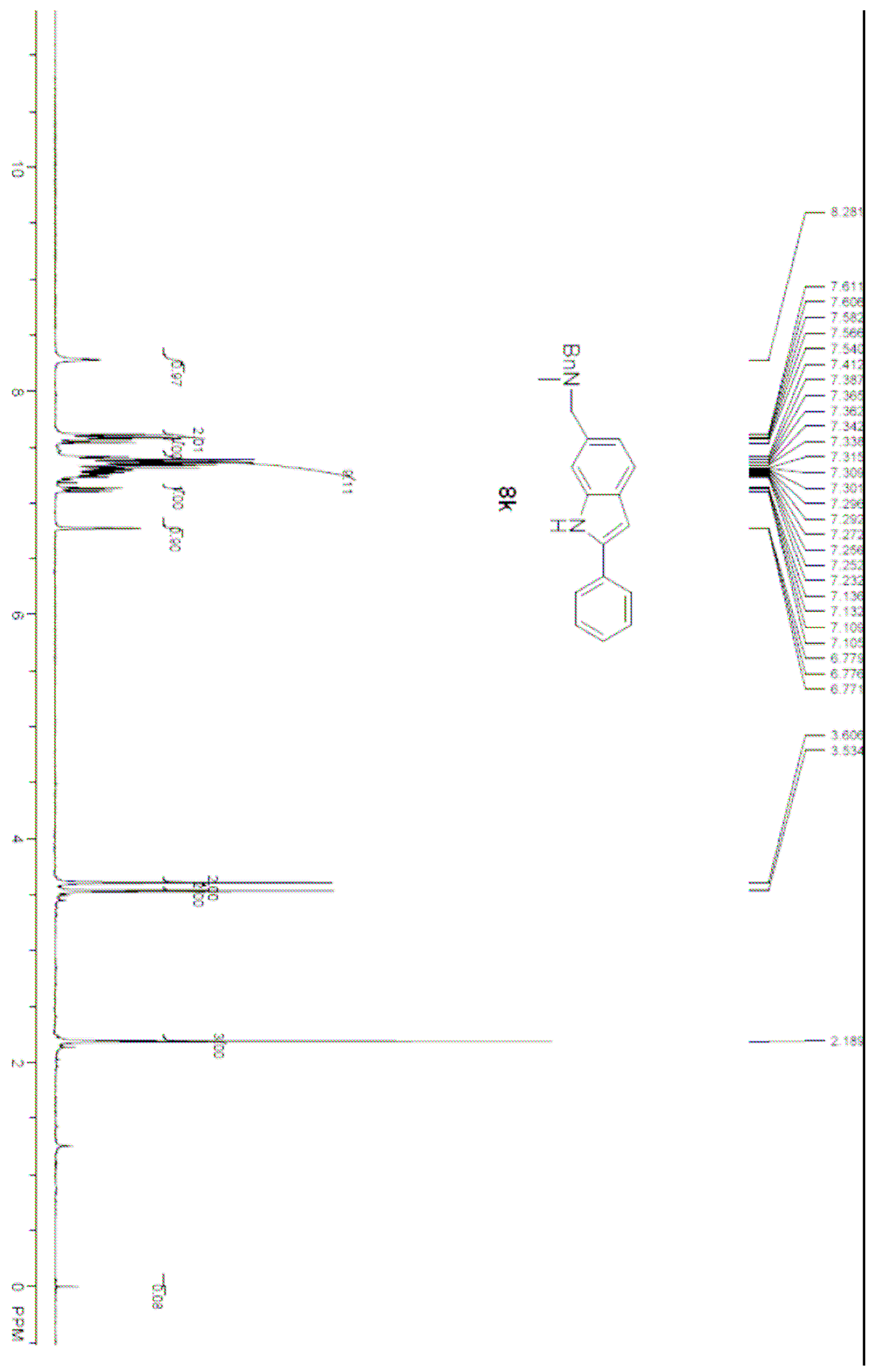

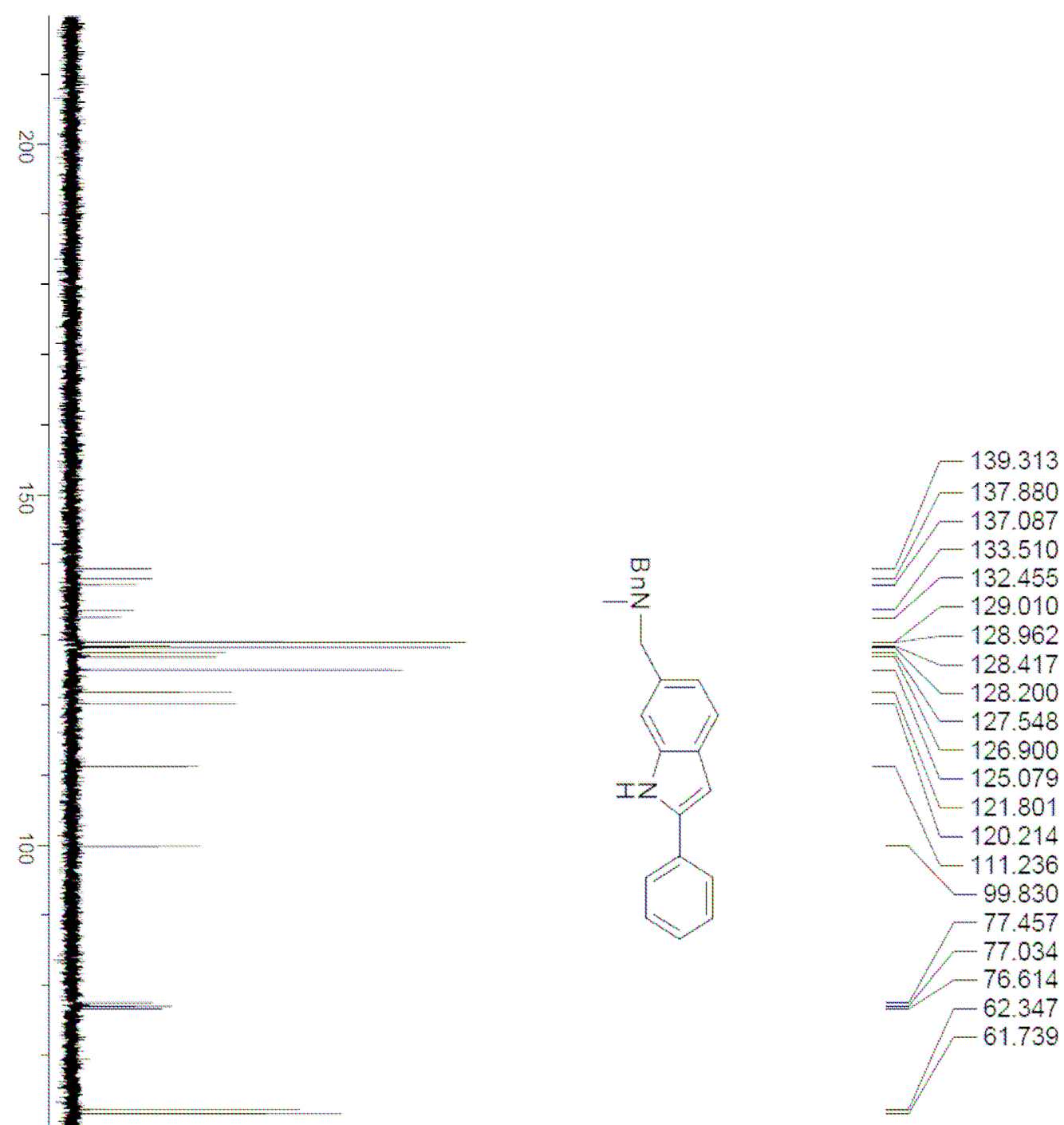

8

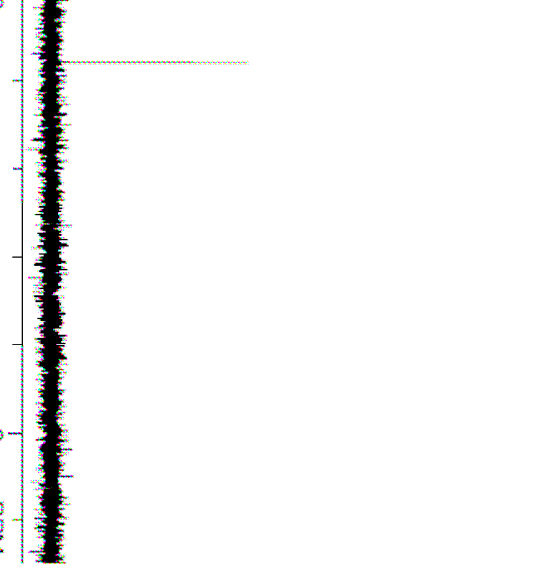

$-42.142$ 

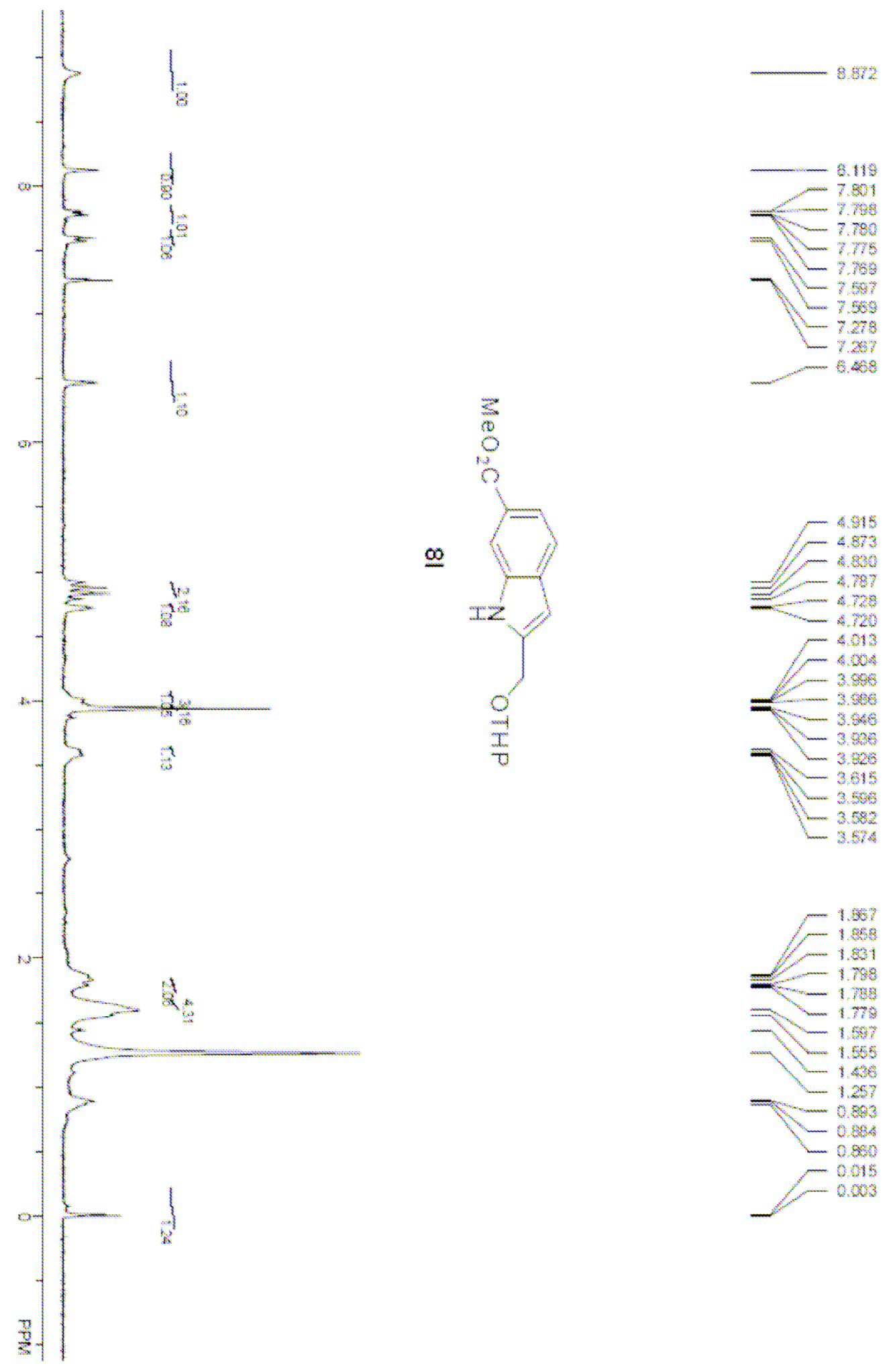

$\underline{\infty}$

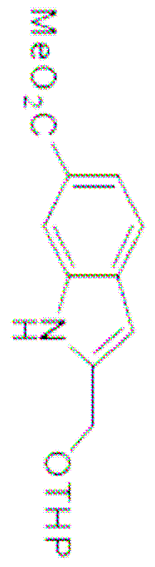

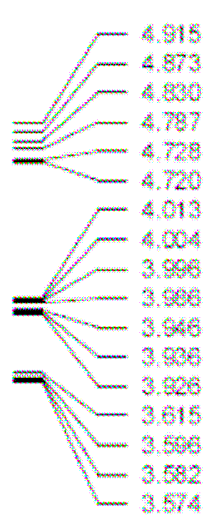

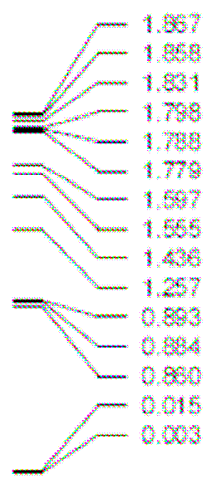




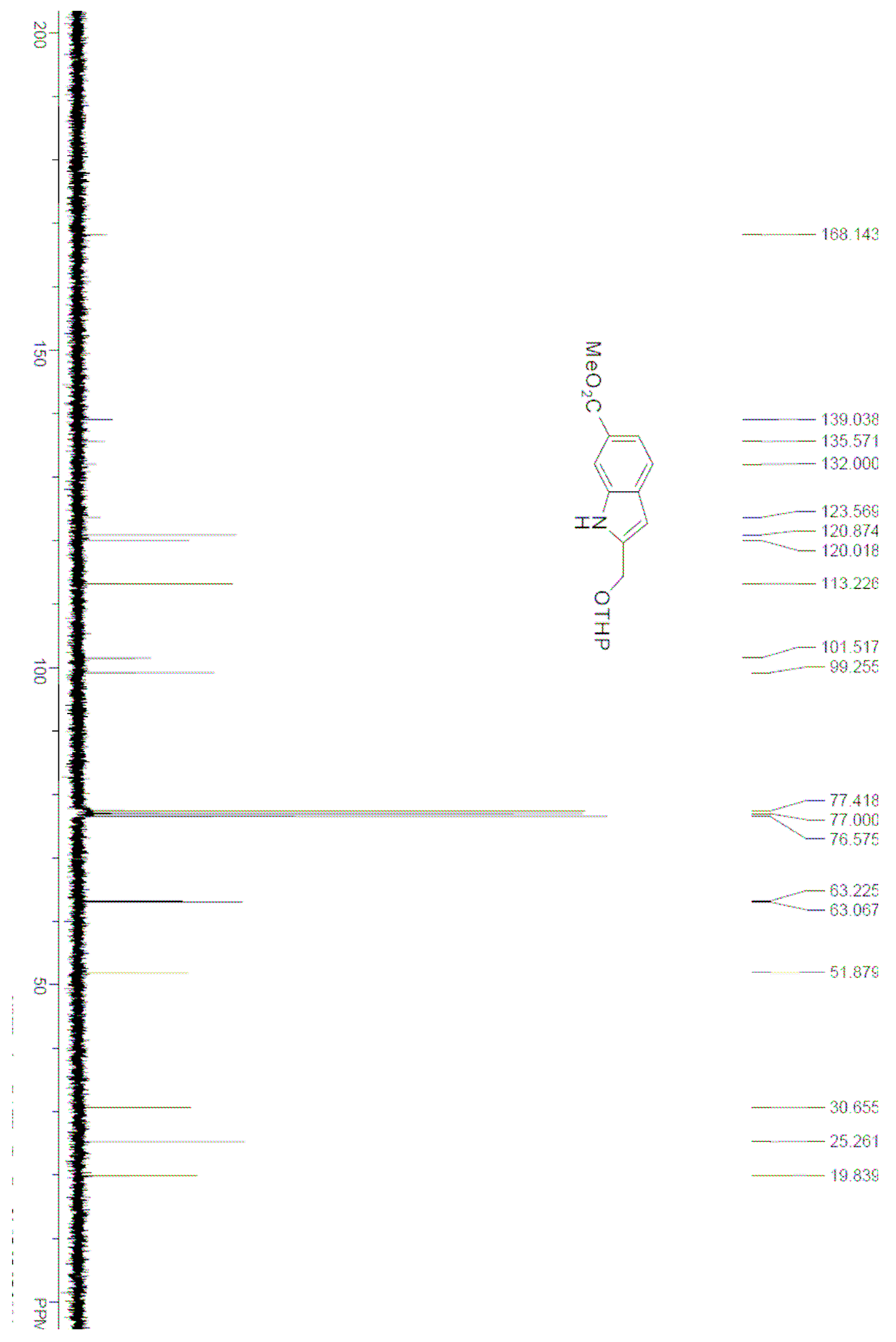




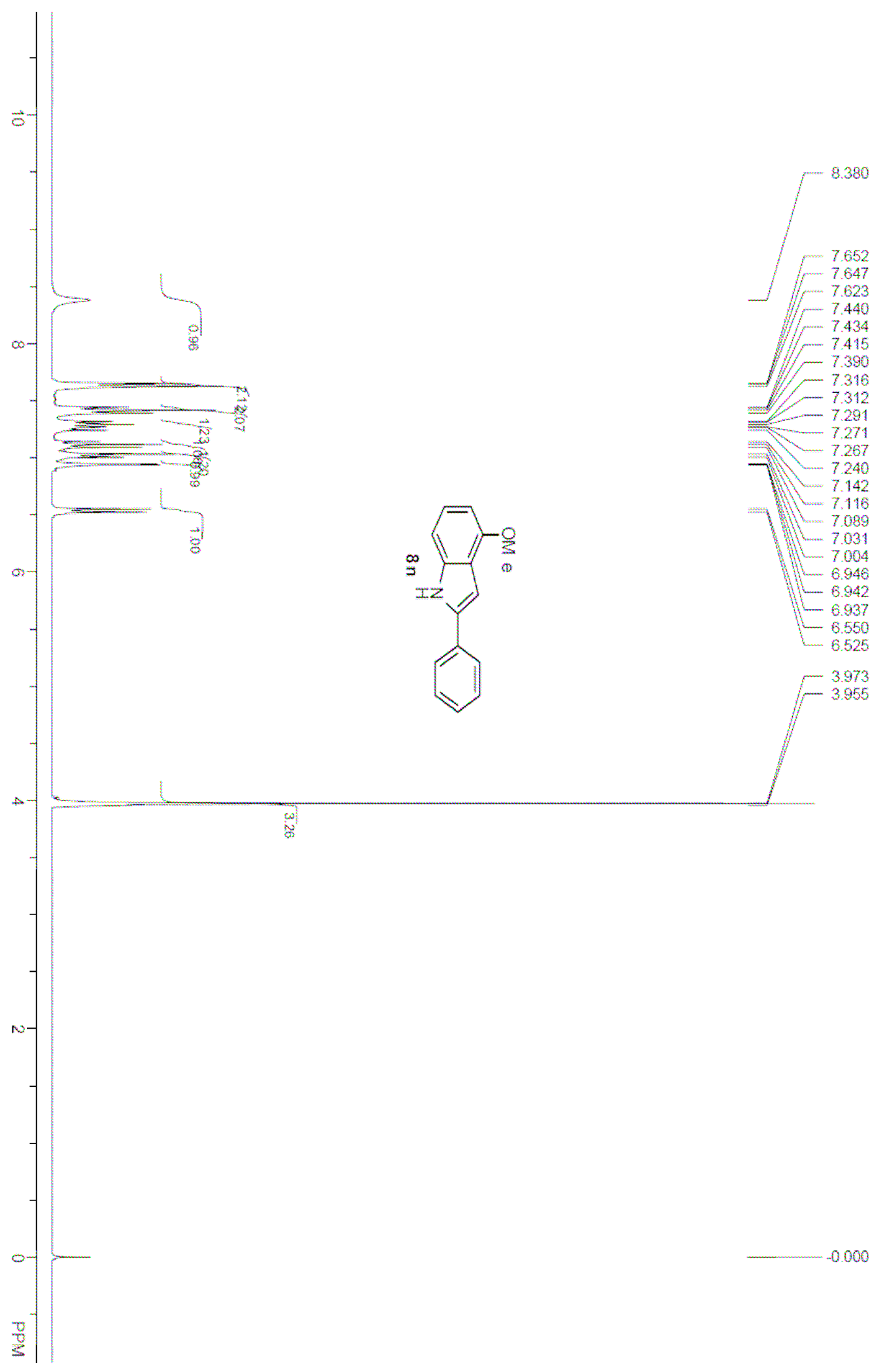



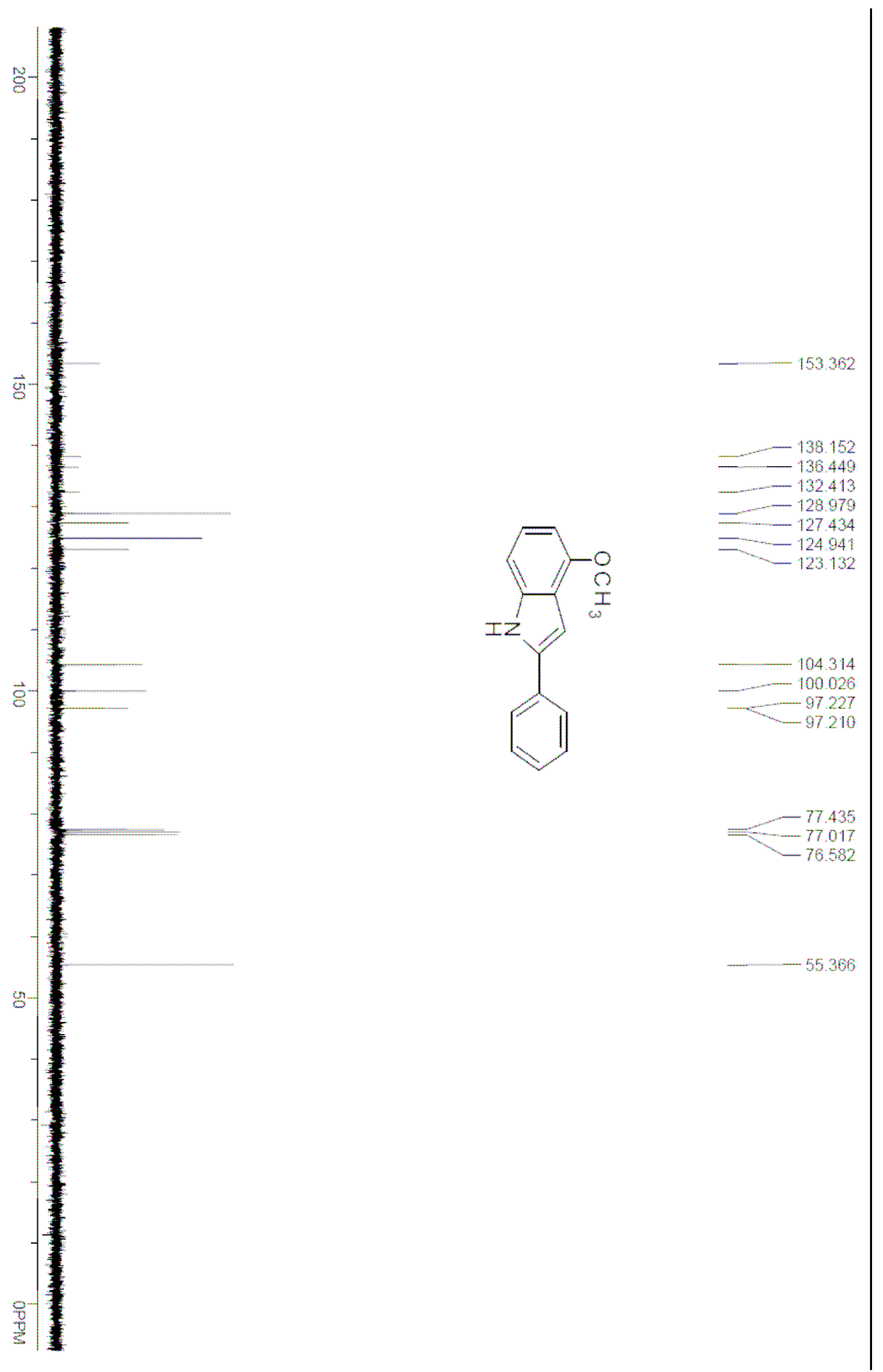


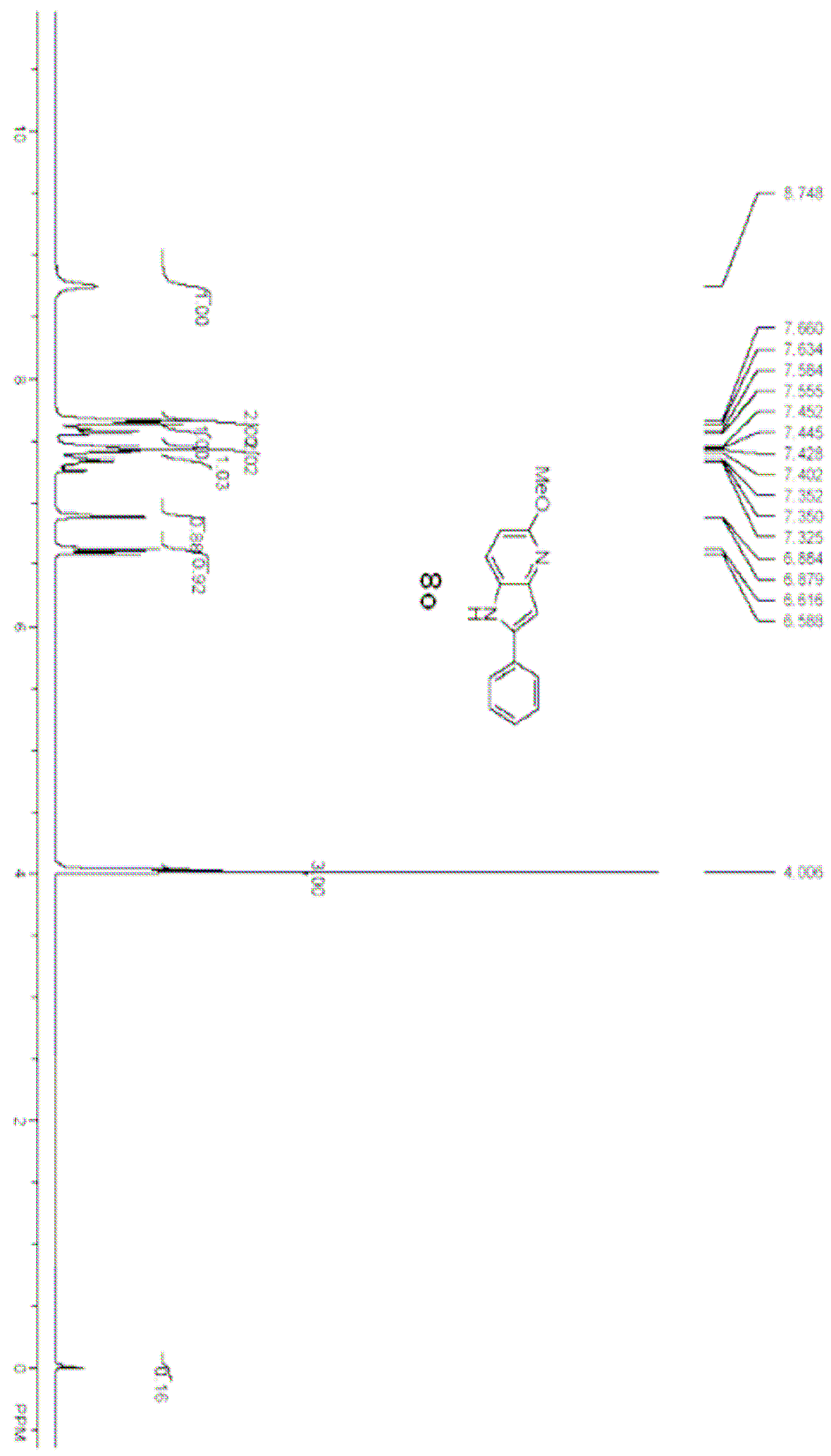




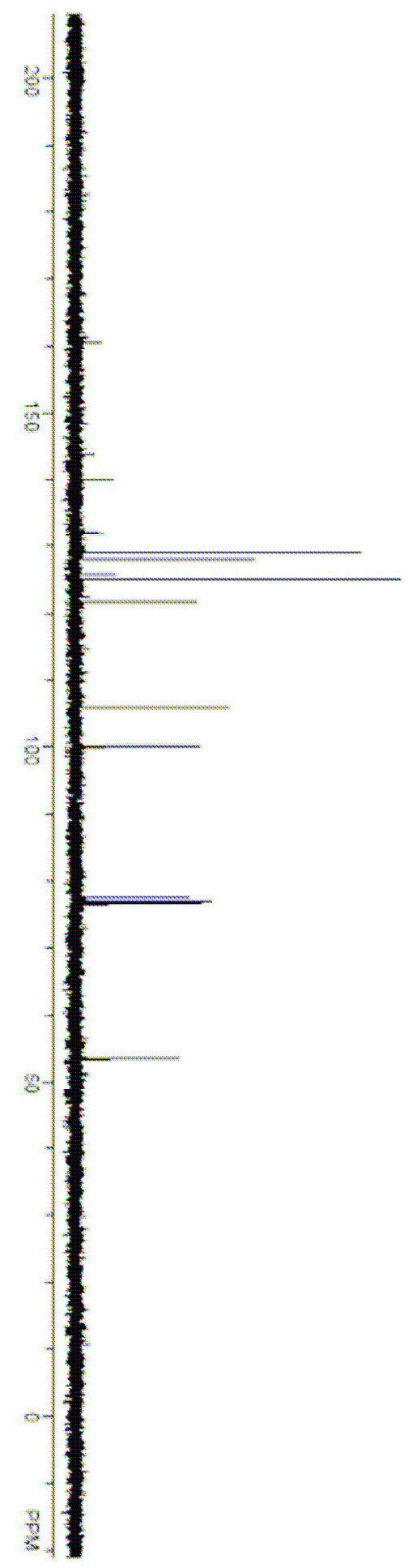

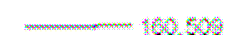

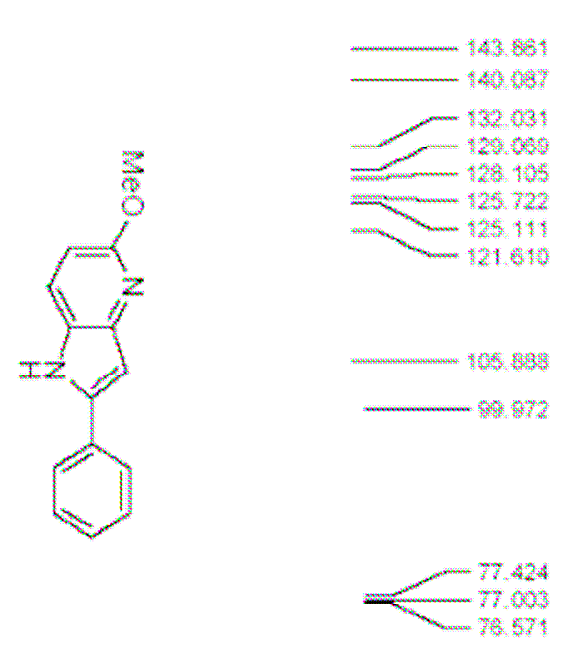

- 134 


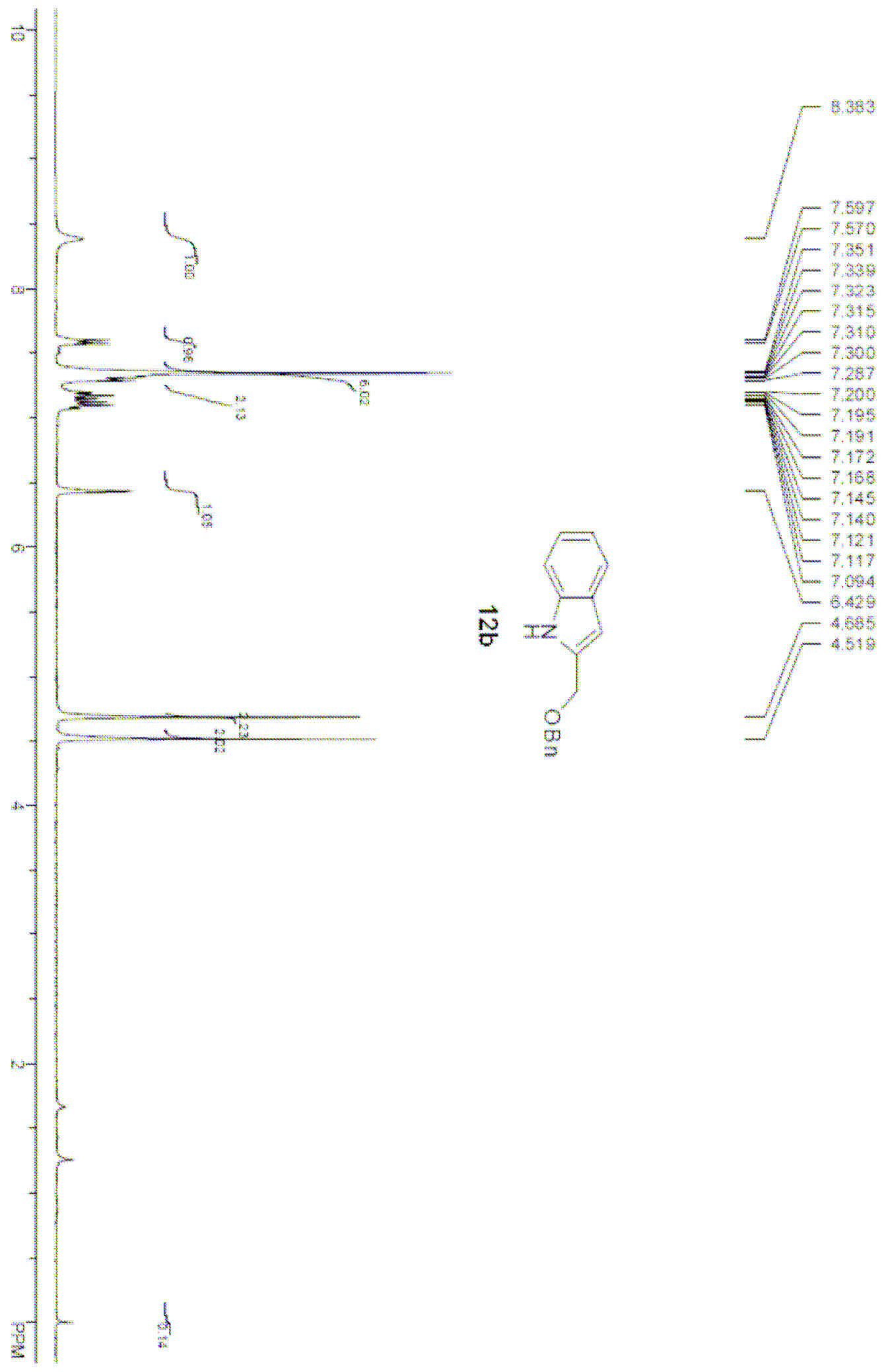



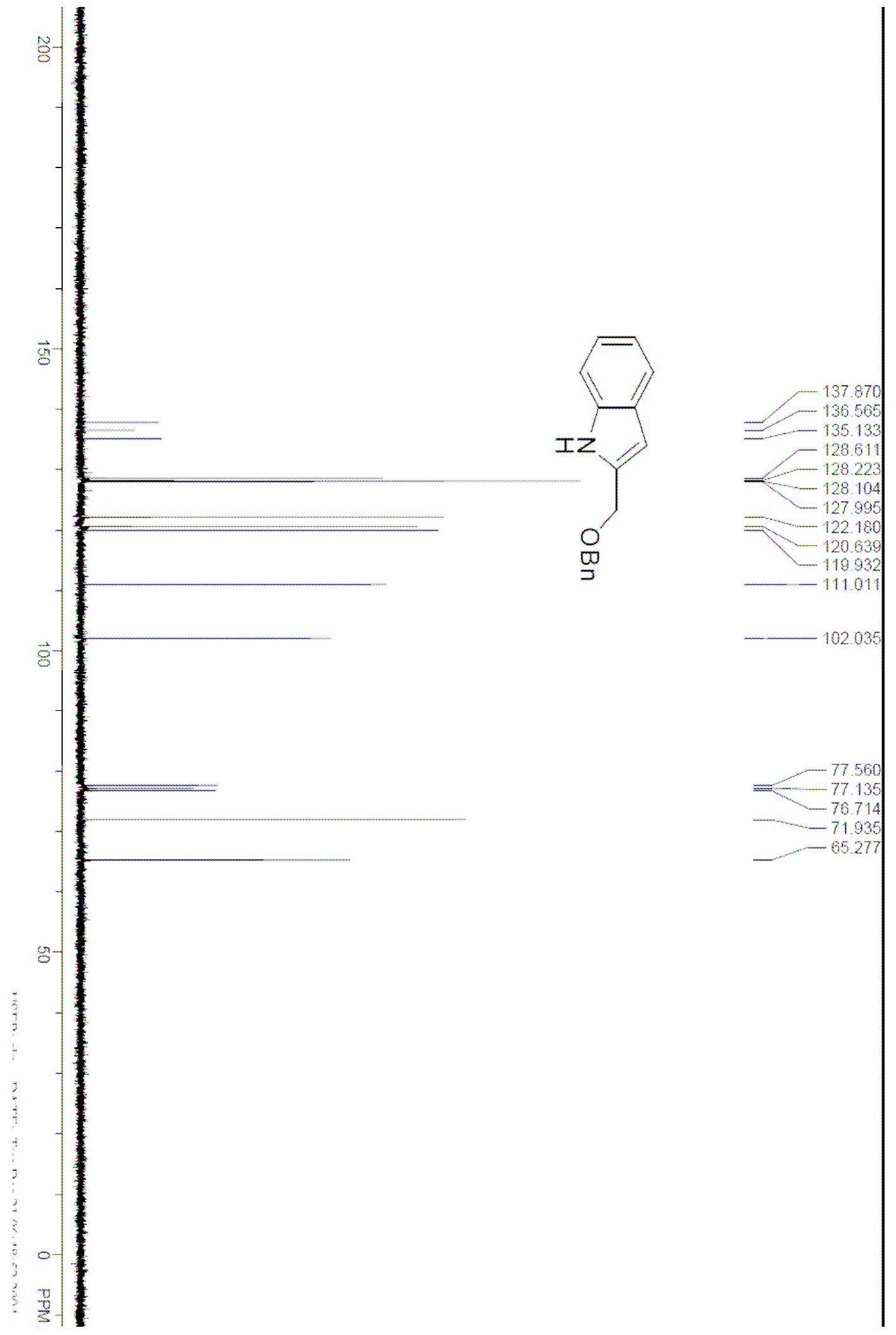

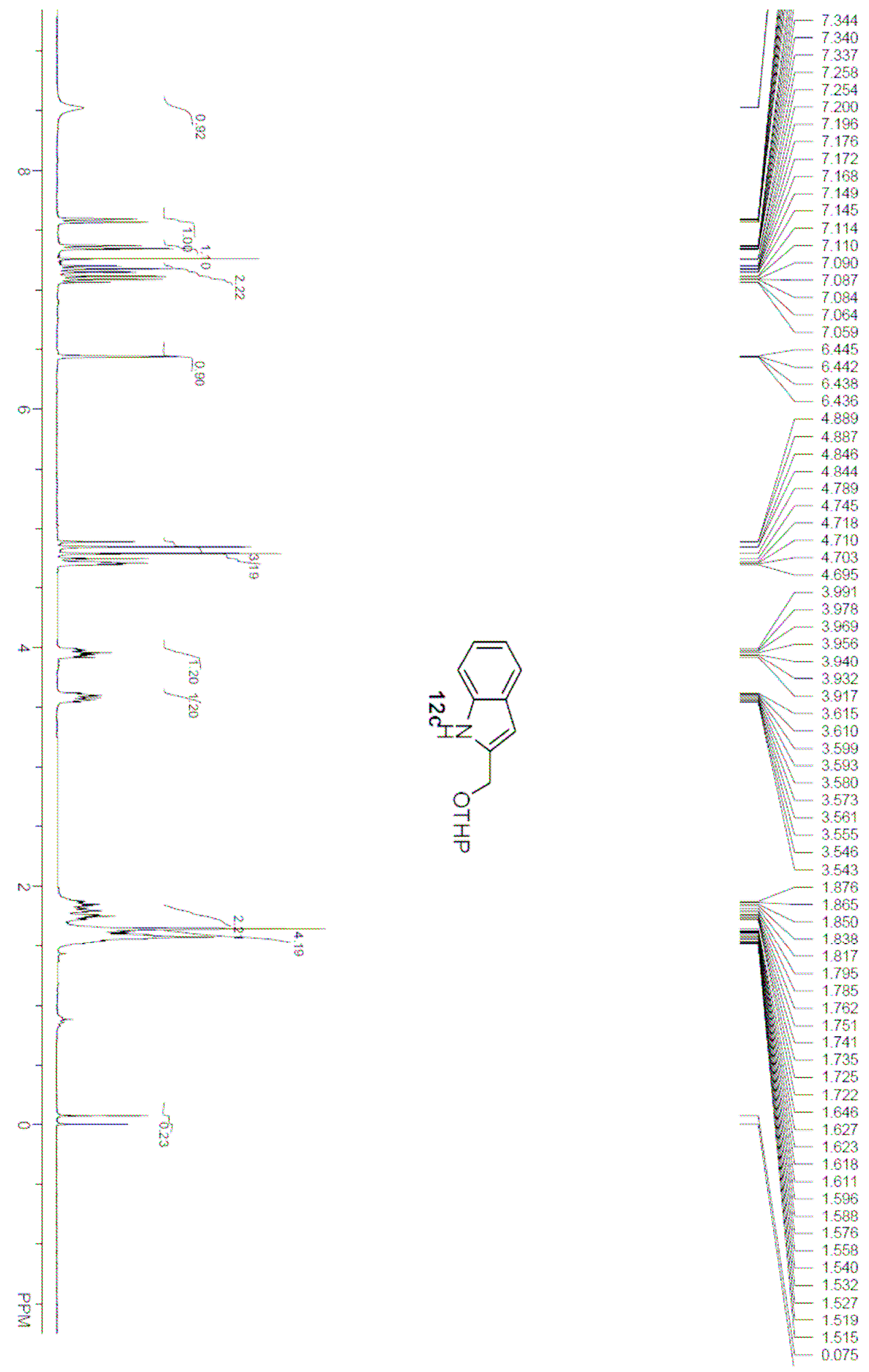


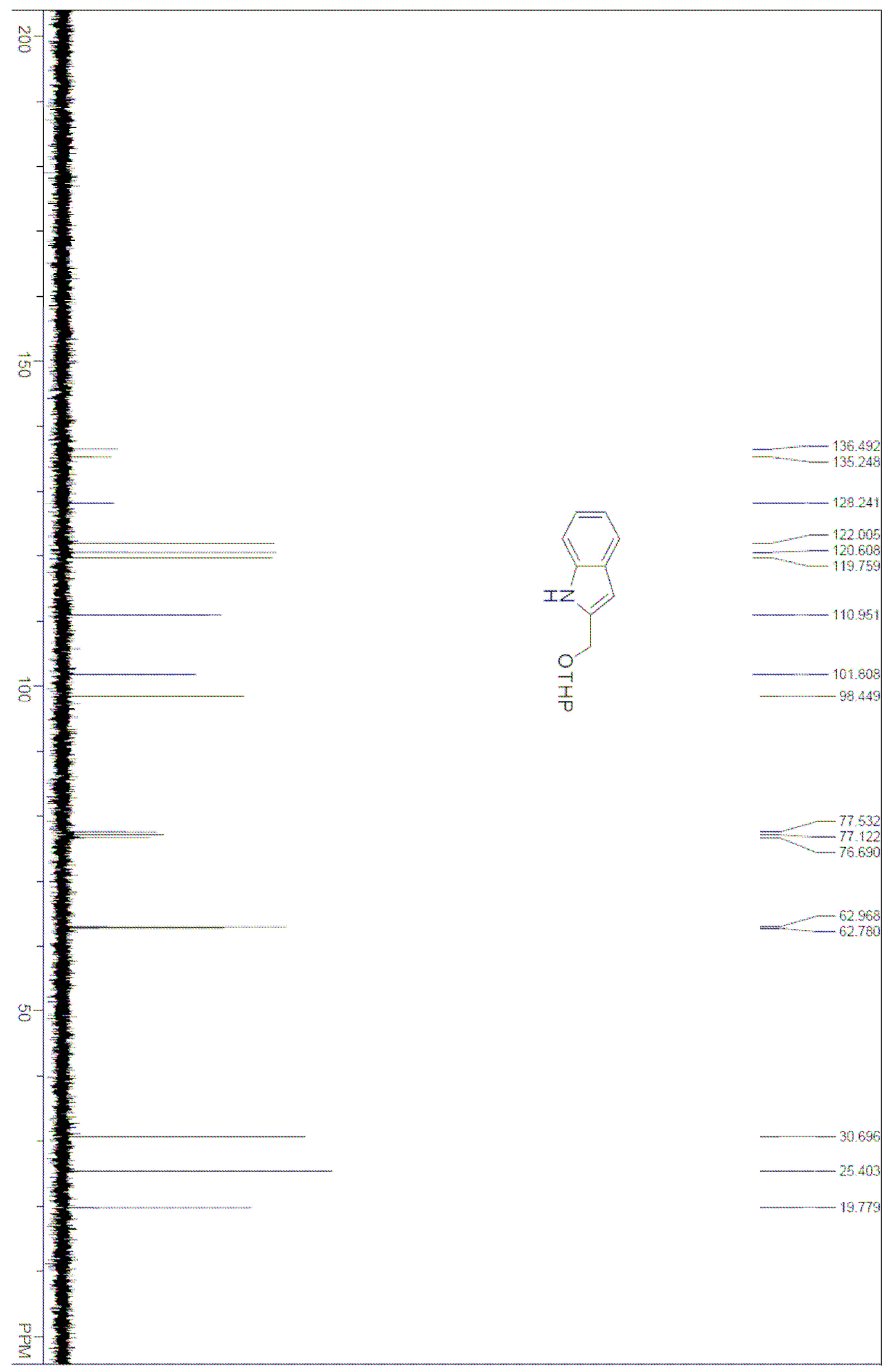




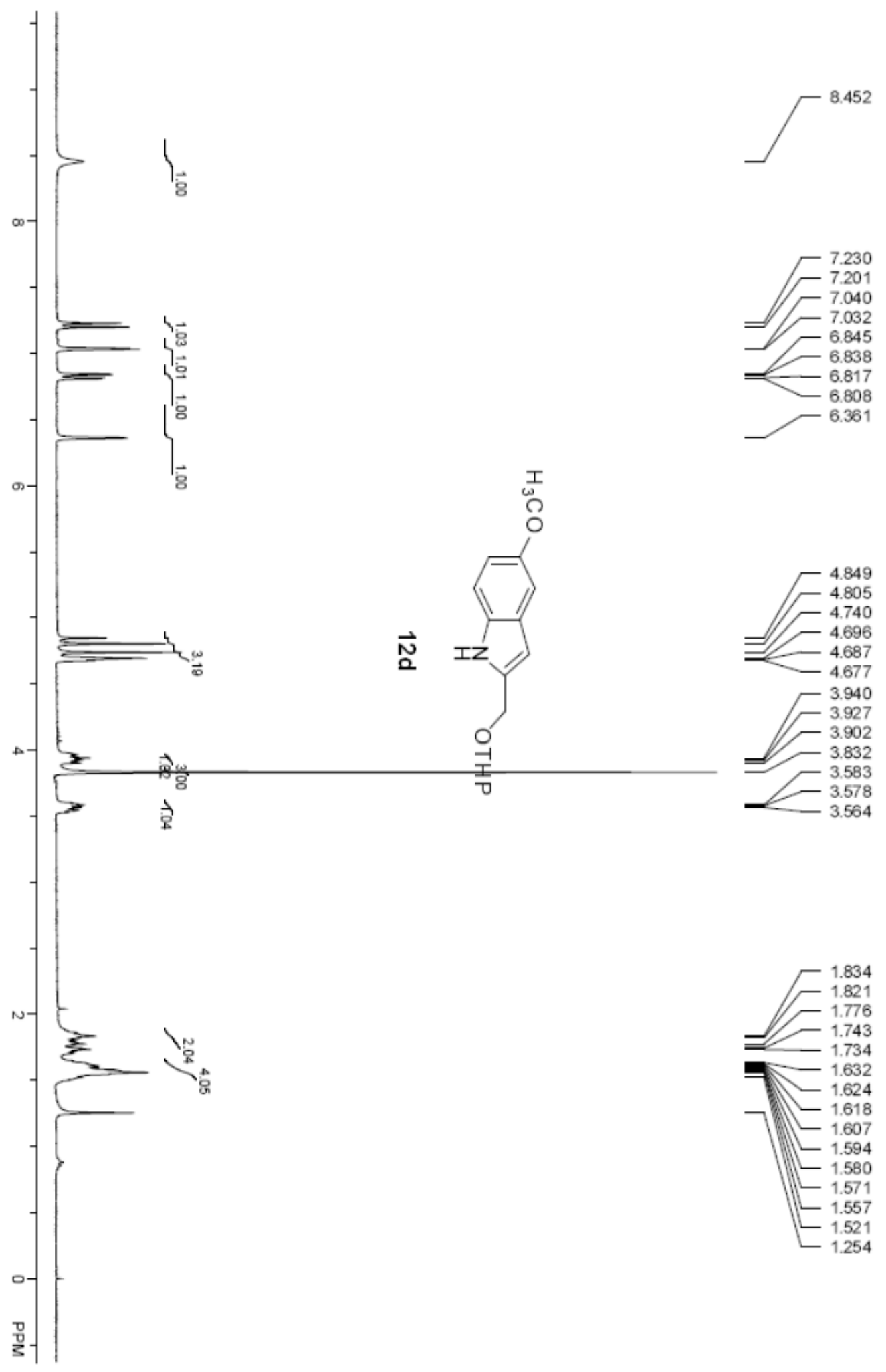



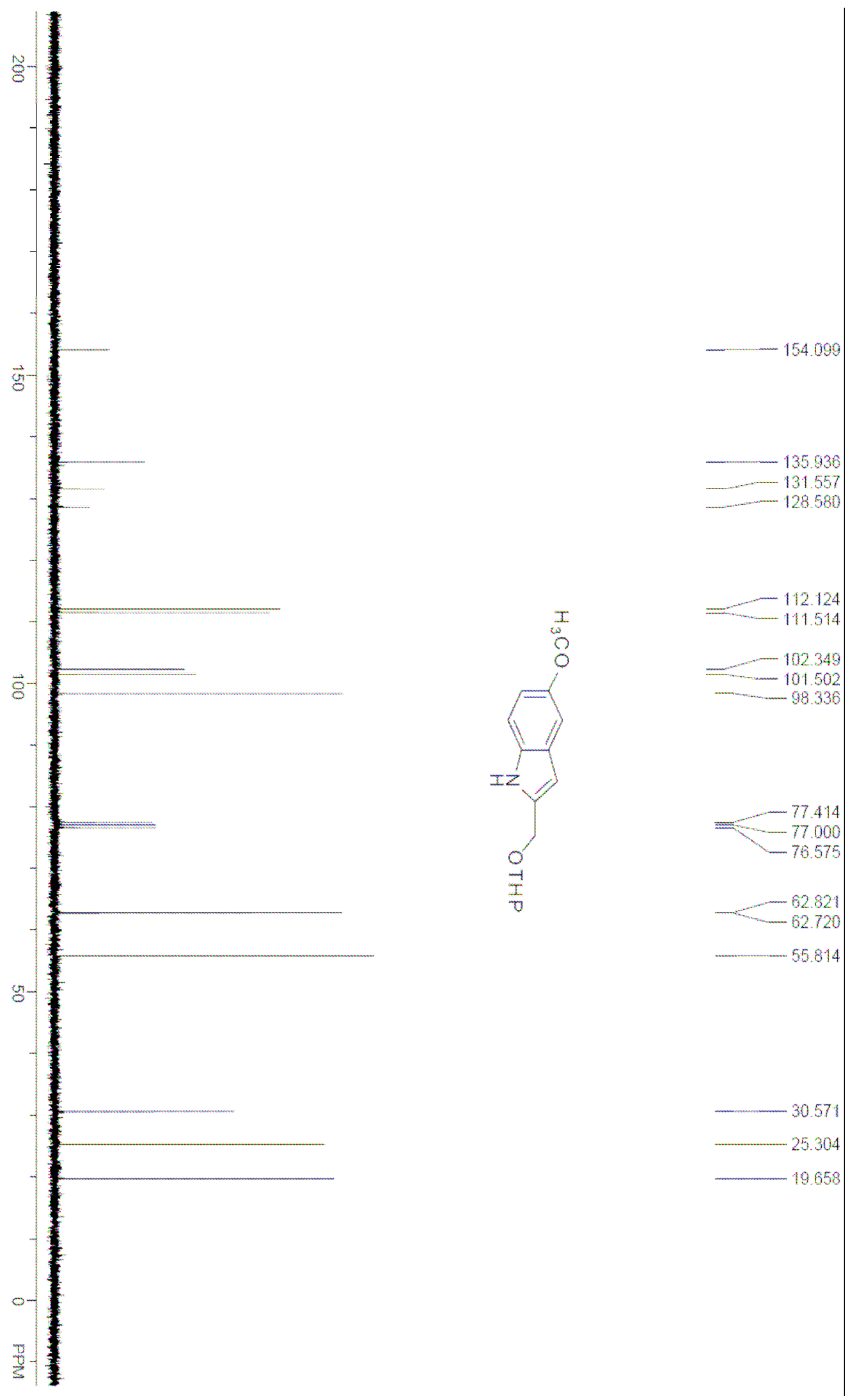

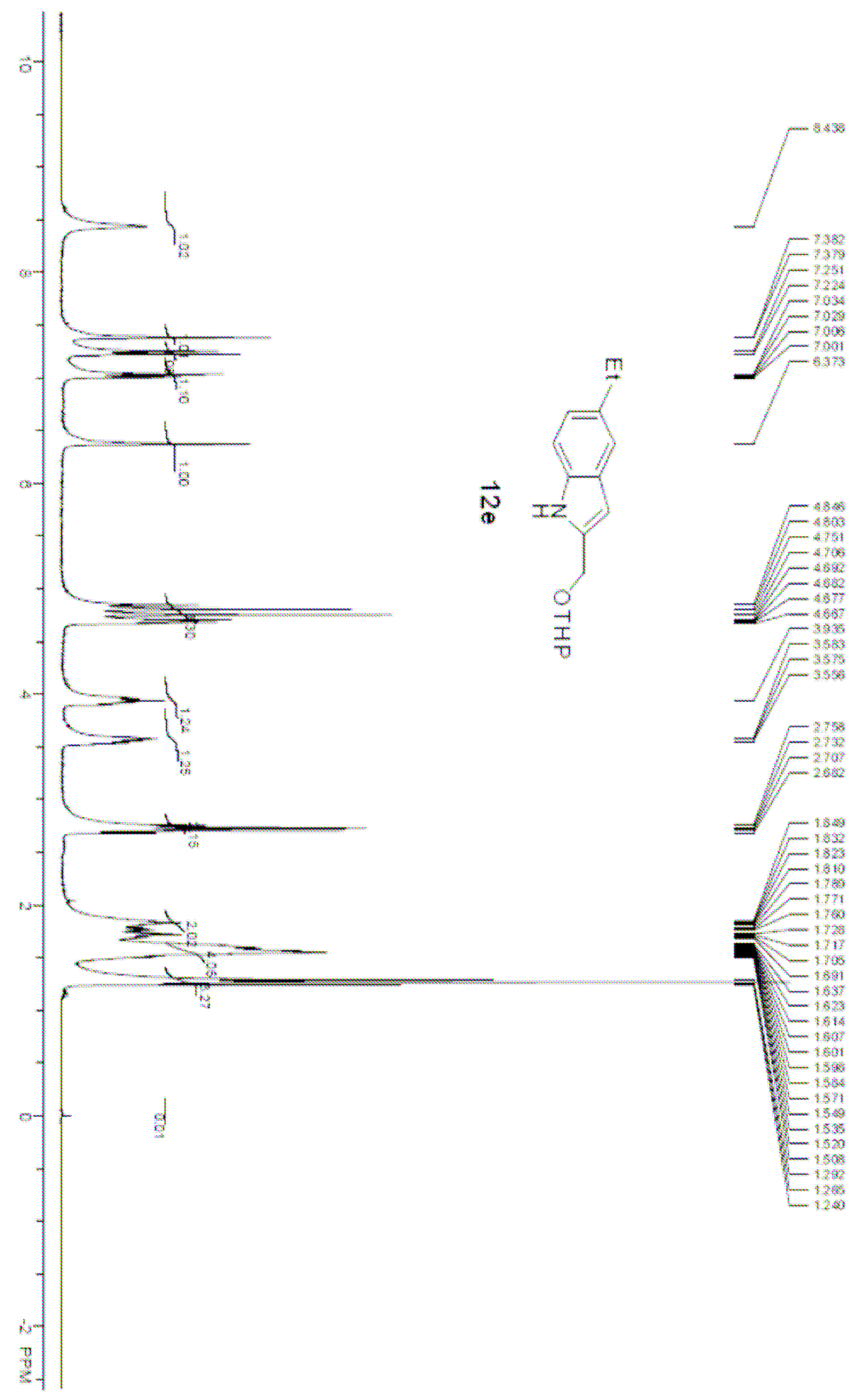

${F^{35}}^{35}$ $1 / 0.55$

$\sqrt{x^{2}}$

$\sqrt{\Gamma^{272}}$ $\sqrt{-270 \%}$

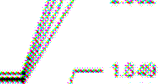

$=1$ - $=15$

$\sqrt{1052}$

$W_{-m-136}$

$y_{y}=13$

-4 $=-17$

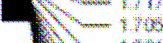

$7 x^{2}-139$

(6) 18

X)

3.

W -

- 158

$8=-5$

$y=150$

$-\frac{150}{150}$

$-120$

-12
-126 

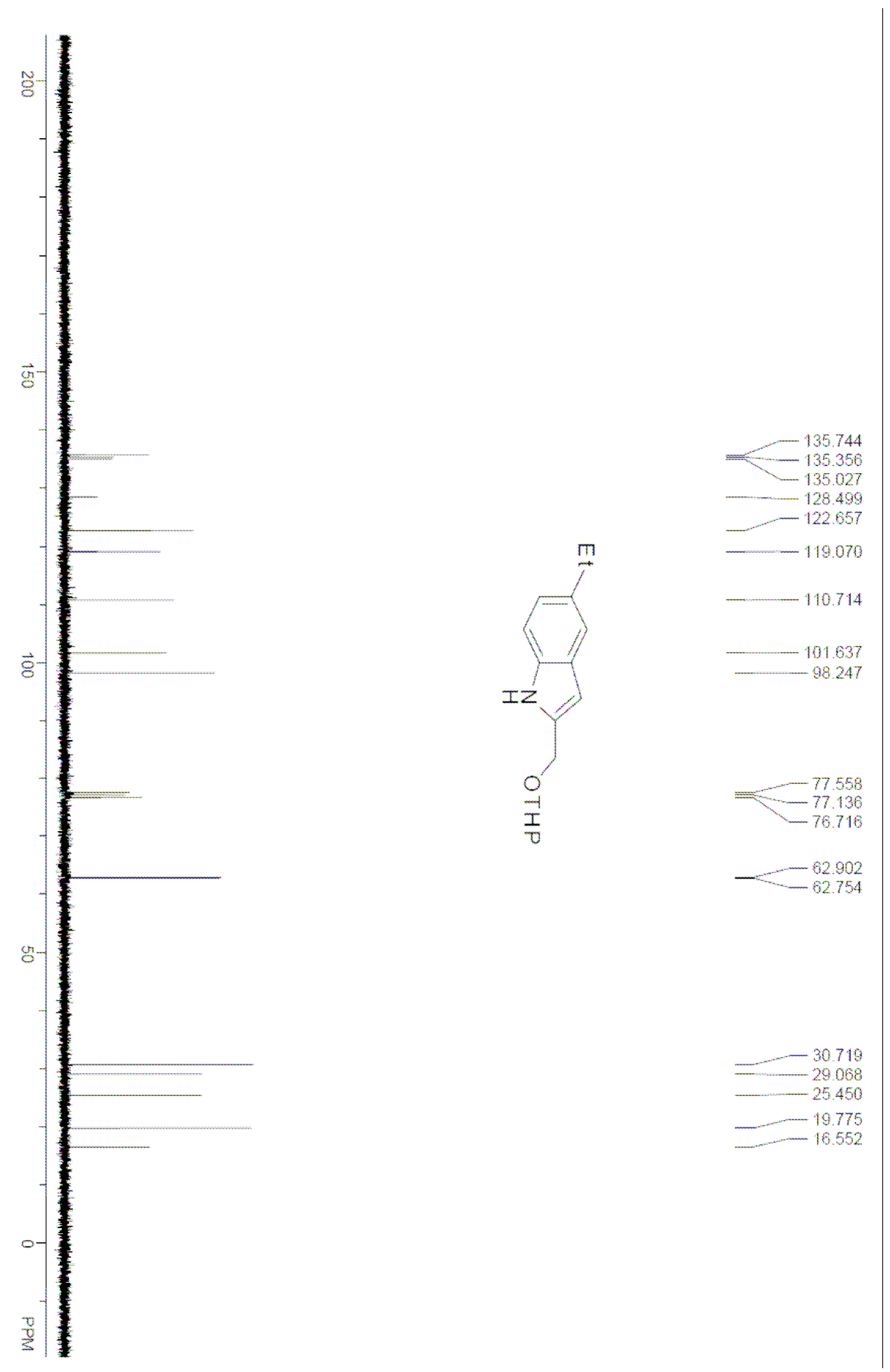

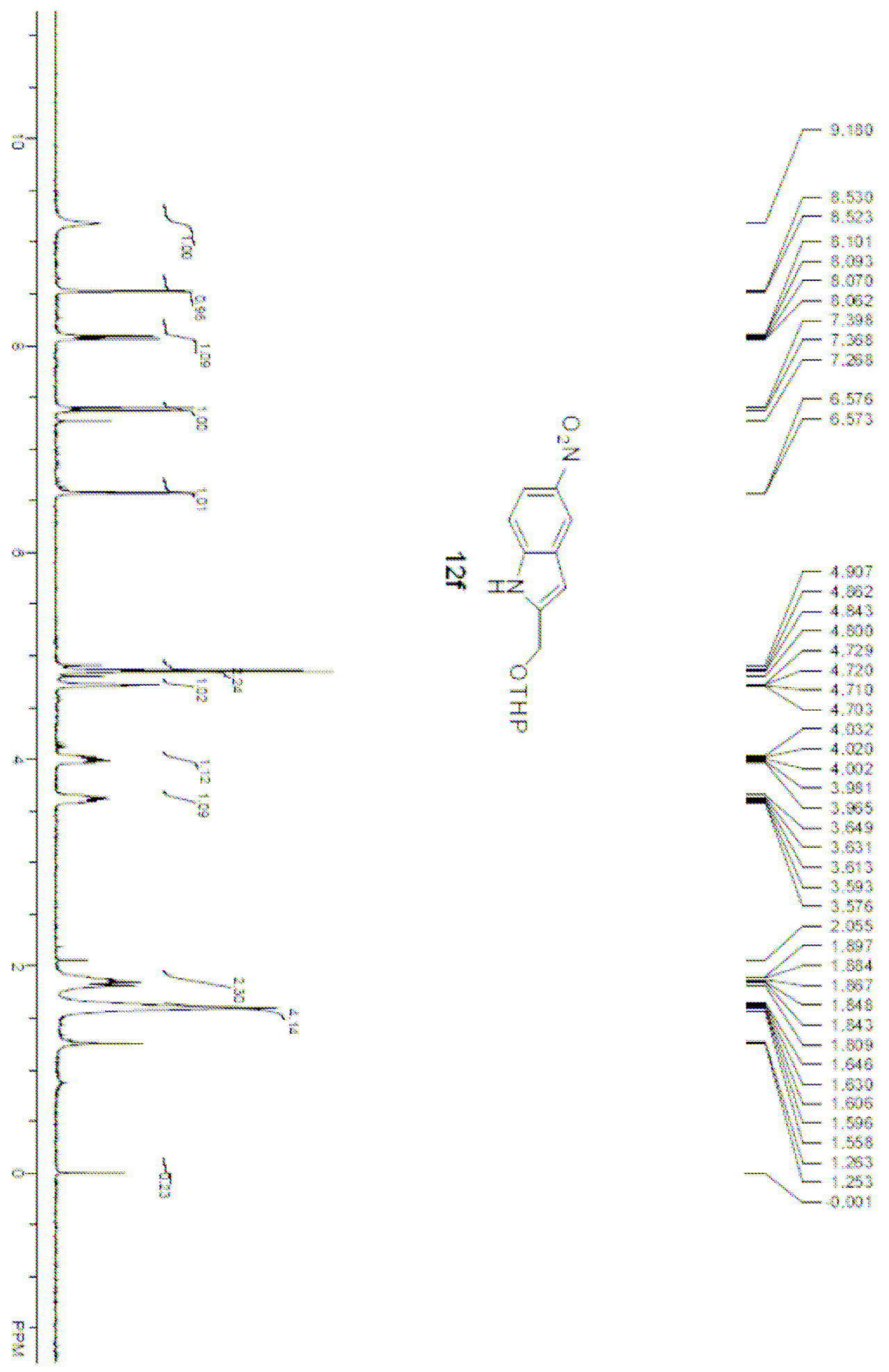

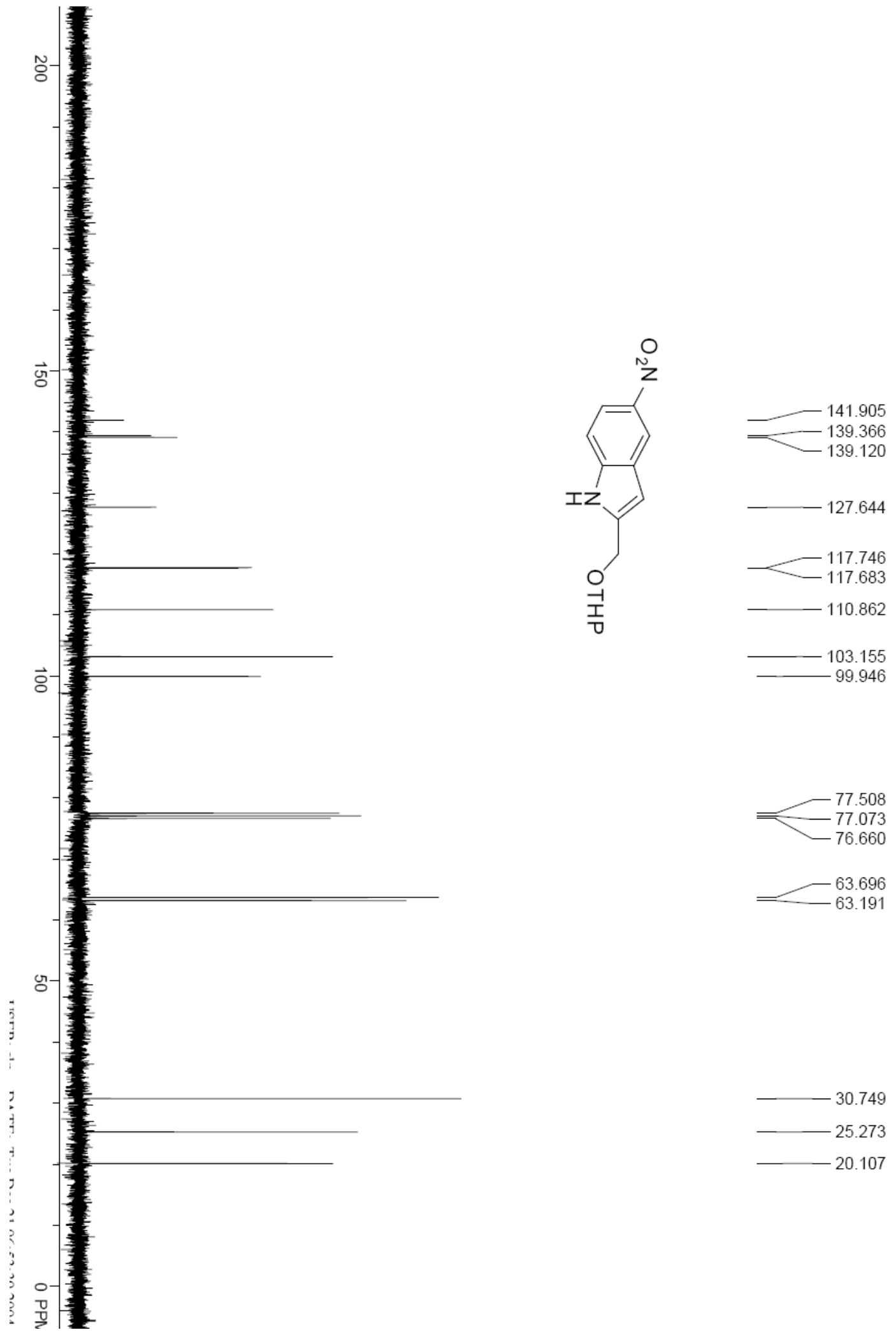

30.749

25.273

20.107 

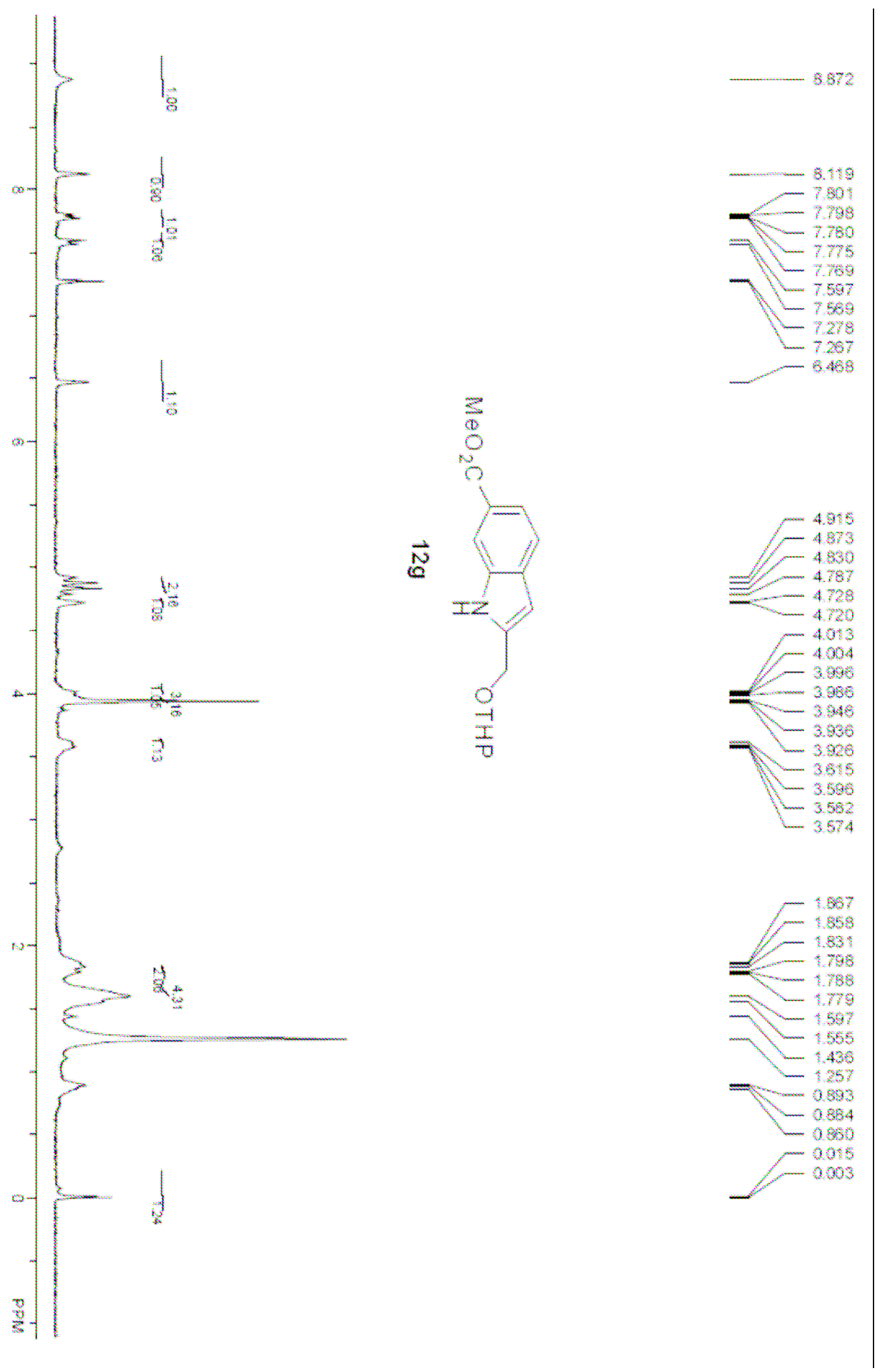


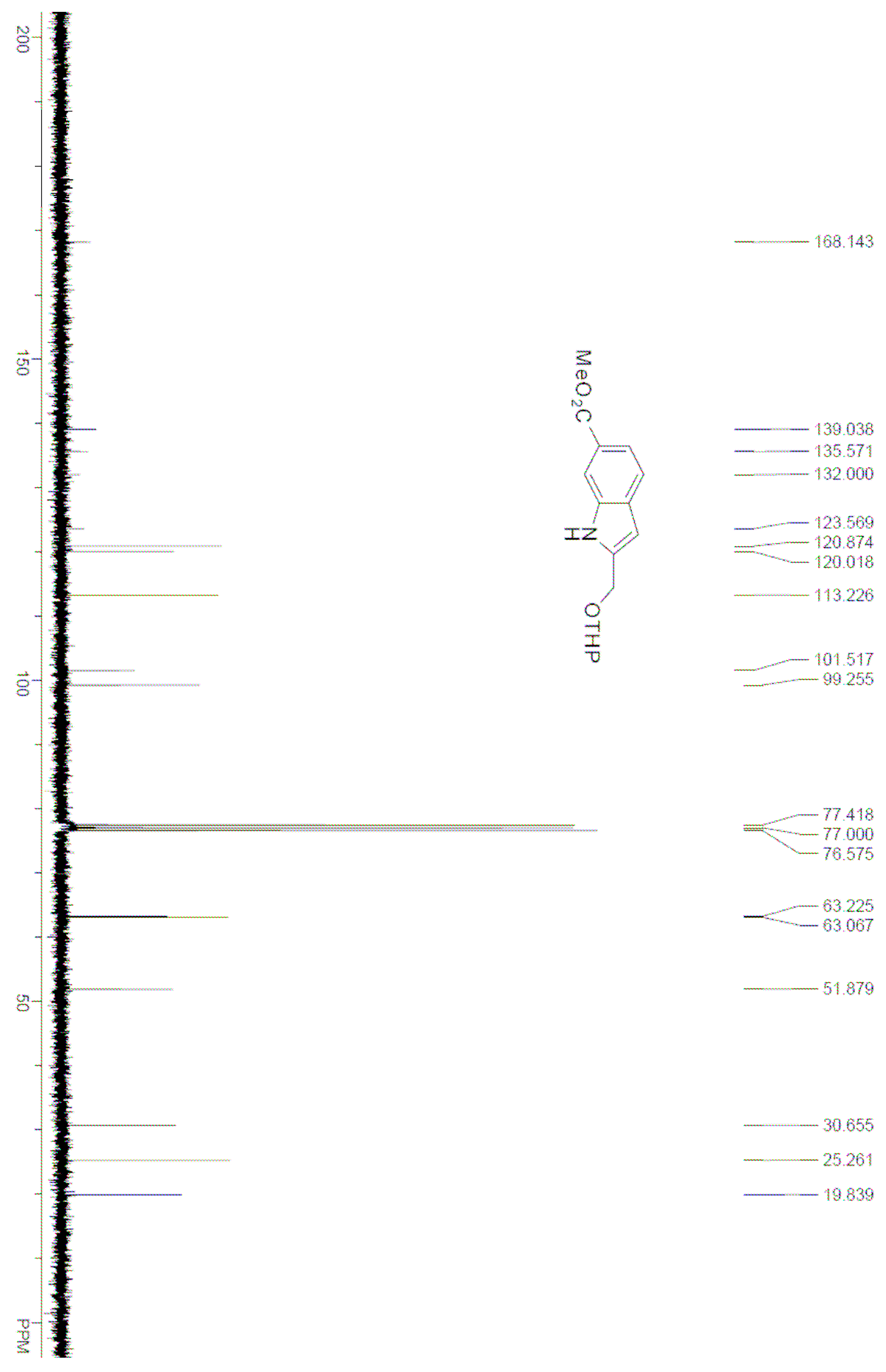

